\title{
Synthesis and characterization of biopolyols through biomass liquefaction of wood shavings and their application in the preparation of polyurethane wood composites
}

\author{
Adam Olszewski $^{1}$ D $\cdot$ Paulina Kosmela $^{1} \cdot$ Łukasz Piszczyk $^{1}$ \\ Received: 8 April 2021 / Accepted: 5 October 2021 / Published online: 22 November 2021 \\ (c) The Author(s) 2021
}

\begin{abstract}
The sustainability of production systems in wood processing, wood industry, and wooden waste disposal is an important issue for European industry and society. Proper development of products based on renewable wood resources gives an opportunity to provide materials with long-term environmental, social, and economic sustainability. This study aims to establish a new way of forestry and agricultural waste materials utilization by synthesis of bio-based polyols and manufacturing of polyurethane wood composites (PU-WC). The first part of this paper describes the liquefaction of wood shavings at a temperature of $150{ }^{\circ} \mathrm{C}$ for $6 \mathrm{~h}$ in three different solvents-glycerol, poly (ethylene glycol) and their mixture in a 1:1 ratio. The second part deals with the synthesis of polyurethane (PU) resins containing $90 \%$ of biopolyol. Eight sets of materials with different $\mathrm{NCO}: \mathrm{OH}$ ratios were obtained in a one-step method using a hydraulic press. These materials were characterized, and the material with the most promising properties was selected for polyurethane wood composites production. Composites with $40 \%, 50 \%, 60 \%$, and $70 \%$ of wood shavings were obtained. The addition of filler caused an increase in flexural strength, Young`s modulus, hardness, and impact strength. Scanning electron microscopy (SEM) showed good adhesion between the polymer and the filler. The optimum filler content is between 50 and $60 \%$ by weight of the composite. The presented study provides a significant step toward a greener alternative for materials produced mainly from non-renewable resources.
\end{abstract}

\section{Introduction}

The problem of wood waste generation and associated risks are increasingly noticeable challenges for modern science. Waste management of post-industrial and post-use waste is one of the difficult problems that Polish society is struggling with. According to the Waste Directive [2018/951/ EC], waste is defined as any substance or object that the holder discards, intends to discard, or is required to dispose of (European Union 2018). We divide wood waste into industrial waste, generated during industrial production and

Adam Olszewski

Adam.Olszewski@pg.edu.pl

Paulina Kosmela

Paulina.Kosmela@pg.edu.pl

Łukasz Piszczyk

Lukasz.Piszczyk@pg.edu.pl

1 Department of Polymer Technology, Chemical Faculty, Gdansk University of Technology, G. Narutowicza St. 11/12, 80-233 Gdańsk, Poland post-use waste. The first group includes shavings, sawdust, bark, wood dust, as well as large and small pieces of wood from processing of wood. The largest sources of wood waste are the sawmill industry $(63 \%)$, the production of particle boards and chipboards (14\%), and the furniture industry (13\%). The most abundant among industrial wastes are sawdust, shavings, and bark (Laskowska 2017). Interpreting data from the European Wood Waste Statistic Report for Recipient and Model Regions (Borzecka 2018), it can be noticed that over 48 million tons of wood waste are generated annually. Only 27.75 million tons of wood waste are recycled or backfilled. The rest of the wood waste is subjected to less preferred waste utilization methods such as incineration and landfilling (Borzecka 2018).

Previously mentioned directive also indicates the waste management hierarchy, which says that preparation for reuse and recycling is more desirable than other recovery processes (e.g., energy recovery) and disposal. It should be emphasized that energy recovery and waste disposal are still widely used in Poland, therefore scientists are looking for new methods of waste management (European Union 2018). One of the known methods of managing wood waste is to 
obtain a full-value product by the production of wood polymer composites (WPC) (Kim and Pal 2010).

WPCs are materials composed of a polymeric matrix and shredded wood, which act as a filler. The most commonly used materials for matrices are thermoplastics such as polyethylene (low and high density), polypropylene, poly (vinyl chloride), or polyurethane (Roig 2018; Friedrich 2021). Moreover, various forms of wood such as splinters, shavings, wood chips, fibers, and wood flour, can be used as the dispersed phase. The amount of wood particles in WPC can reach up to $80 \%$ of the weight of the composite. However, due to the high moisture absorption, it may be limited. High water adsorption may result in debonding and decrease in the mechanical properties of the material. To improve the properties of these materials, coupling agents, which improve compatibility between the polymer phase and the dispersed wood phase, auxiliary agents such as antioxidants, UV stabilizers, biocides, and flame retardants can be used (Ndiaye et al. 2013). High content of wood in WPC contributes to the limited use of petrochemical polymers. The latest results (Friedrich 2018) suggest that these materials have almost neutral cradle-to-gate $\mathrm{CO}_{2}$-balance. This hypothesis is based on the fact that before processing, wood fibers absorb greenhouse gases from the atmosphere. The amount of absorbed gas is equal to gas emitted during the utilization of this material. Due to environmental protection, it is desirable to use as much as possible renewable resources in the production of WPCs. Possible solutions can be the use of biopolyols, obtained through the liquefaction process in the production of a polyurethane matrix.

Liquefaction is the process of converting solid biomass into liquid. It can run indirectly, where it is first converted into a syngas, from which alcohols and alkanes are synthesized. Direct liquefaction occurs in protic solvents such as water, phenols or low carbon alcohols. This is the main method of biomass conversion because of the milder reaction conditions which enables easier process control and higher efficiency (Guo et al. 2019). Biopolyols synthesis via liquefaction process consists of the biomass reaction with a solvent in the form of polyhydric alcohol. This reaction is conducted with the addition of catalyst. Types of solvent and catalyst take an essential role during the liquefaction process. This process is generally conducted at temperatures $\left(120-250{ }^{\circ} \mathrm{C}\right)$ under atmospheric pressure. As a reaction solvent polyhydric alcohol, such as polyethylene glycol (PEG) with different molar mass, and glycerol are mainly used (Hu et al. 2012; Kosmela et al. 2016). The liquefaction of biomass can be accelerated by the addition of an appropriate catalyst. During the reaction, acid and base catalysts can be used. To this date, it was demonstrated that concentrated sulfuric acid shows the highest catalytic activity during biomass liquefaction (Wang and Chen 2007). In this process, the lignocellulosic biomass decomposes through solvolysis reaction into smaller molecules. This leads to the generation of a wide range of substances, which consist of hydroxyl groups. The most important of them are glycosidic alcohols, which in the next stage can transform into levulinates, furfural, and 5-hydroxymethyl furfural (Deng et al. 2010; Hu et al. 2014; Guo et al. 2019). Few studies have explored the use of bio-based polyols in the production of polyurethane foams and adhesives. Gama et al. (2017), in their study, synthesized coffee ground derived polyols, which were used in the production of sound-absorbing polyurethane foams with high thermal stability. Zhang et al. (2019) demonstrated the optimalization of agricultural waste liquefaction process by changing the reaction conditions. The authors transformed four agricultural wastes into polyols with high biomass conversion. These polyols were used for the production of polyurethane foams and showed comparable properties in comparison with petroleum-based foams. Vale et al. (2019) provide a detailed pathway for the development of ecological polyurethane foams with an addition of biopolyols. These polyols were obtained from liquefaction of industrial by-products, such as cork powder and eucalyptus bark. Despite this interest in the production of polymeric foams, only a few studies have explored the use of bio-based polyols in the synthesis of crosslinked un-foamed polyurethane materials. It has not yet been established whether these materials are suitable for the production of composites with the addition of wood.

Previous studies showed the possibility of using the obtained biopolyols in the production of cross-linked non-foamed polyurethane materials (Gosz et al. 2021) and composites with an addition of organic (e.g., sisal fiber) (Olszewski et al. 2020) and inorganic fibers (e.g., glass and carbon fiber) (Olszewski et al. 2021). To date, no studies have been carried out on the addition of wood fibers to polyurethanes obtained with the addition of biopolyols. These materials could be used in furniture, automotive, and construction industries as ecological panels, terrace boards, table tops, and laminates. These products could be a greener alternative to materials produced mostly from non-renewable resources.

In this work, three biopolyols were prepared by liquefaction of chip waste at a temperature of $150{ }^{\circ} \mathrm{C}$ for $6 \mathrm{~h}$ in three different solvents. To accelerate the process, $3 \% \mathrm{wt}$. of sulphuric acid $\left(\mathrm{H}_{2} \mathrm{SO}_{4}\right)$ as a catalyst was added. Then, the polyols were neutralized and dried under reduced pressure. To obtain the materials, a mixture of biobased and petrochemical polyols was used. Materials with different NCO$\mathrm{OH}$ ratios were manufactured and tested. The material with the most promising properties was used for the preparation of polyurethane wood composites (PU-WC). In the production of composites, milled wood shavings of different wood species (WS) were used as a filler. 


\section{Experimental}

\subsection{Materials}

The mixed wood shavings were obtained from a local sawmill (Gdańsk, Poland). The wood waste was milled, divided by size, and then dried in an oven at a temperature of $100{ }^{\circ} \mathrm{C}$ for $24 \mathrm{~h}$. As a liquefaction solvent, polyethylene glycol (PEG 400) supplied by POCH S.A (Gliwice, Poland) and refined crude glycerol acquired from Bio-Chem sp. z o.o. (Olszanka, Poland) were used. Concentrated $95 \%$ sulfuric acid was purchased from Avantor Performance Materials Poland S.A (Gliwice, Poland). Petrochemical polyol Rokopol ${ }^{\circledR}$ M6000 (polyoxyalkylene triol based on glycerol, $\mathrm{LOH}=28 \mathrm{mg}$ $\mathrm{KOH} / \mathrm{g}$ ) was supplied by PCC Rokita S.A (Brzeg Dolny, Poland) and polymeric methylene diphenyl diisocyanate (pMDI, 31\% free NCO groups) was provided by Borsodchem (Kazincbarcika, Hungary). Dibutyltin dilaurate 95\% and Dabco ${ }^{\circledR} 33-\mathrm{LV}$ were purchased from Sigma-Aldrich (Saint Louis, MO, USA). All reagents were used without any further purification steps.

\subsection{Two-step preparation of bio-based polyols}

The liquefaction of the mixed chip waste was carried out in a three-neck reactor under atmospheric pressure. The mixture was stirred constantly using a mechanical stirrer. The reactor was heated by a heating mantle. In this reaction, glycerol, PEG 400, and 50/50\% wt. a mixture of PEG400 and glycerol were used as a solvent. To catalyze the reaction, $3 \%$ wt. of 95\% sulfuric acid was added. The mass ratio of chip waste to the solvent was 1:10. In the first step, the liquefaction was conducted using three different solvent systems to determine the impact of solvent structure on the course of the reaction and the properties of polyols. Samples of the product were collected every hour to determine the change of hydroxyl number and biomass conversion during reaction. In the second step, the obtained product was neutralized with sodium hydroxide $(\mathrm{NaOH})$, and then dried under vacuum for $2 \mathrm{~h}$ to remove excess water.

\subsection{Preparation of polyurethane materials and polyurethane wood composites (PU-WC)}

All materials were manufactured in one-step method using a two-component system. Before the manufacturing of the composites, wood shavings were dried at $100{ }^{\circ} \mathrm{C}$. Wood shavings were mixed with $90 \%$ of biopolyol and $10 \%$ of M6000. As a catalyst, $0.5 \%$ by weight of Dabco ${ }^{\circledR} 33-\mathrm{LV}$ and dibutyltin dilaurate were added. Component $\mathrm{B}$ was pure pMDI. Both components were mixed. After that, the mixture was poured into the steel mould and hot pressed for $15 \mathrm{~min}$ at $100{ }^{\circ} \mathrm{C}$ under a pressure of $10 \mathrm{MPa}$. To cool down and keep the shape of the samples, the materials were cold pressed for $10 \mathrm{~min}$ under a pressure of $10 \mathrm{MPa}$. Eight sets of materials with a different ratio of $\mathrm{NCO}: \mathrm{OH}$ without filler and four sets of PU-WC were fabricated from selected polyols with different additions of wood shavings as shown in Table 1.

\subsection{Characterization}

\subsubsection{Physical properties}

To determine the water content in wood waste, the moisture analyzer Radwag MA 50/1.X2.A was used. Analysis of the size distribution of the wood particles was carried out using a laboratory shaker with a set of sieves. The hydroxyl number of the polyols was determined according to the PN93/C-89,052/03. The polyol samples in the conical flasks were dissolved in acetylation mixture and then placed in a steam bath. After $30 \mathrm{~min}, 1 \mathrm{ml}$ of pyridine was added to the mixture. After another $10 \mathrm{~min}, 50 \mathrm{ml}$ of distilled water was added. Then, a titration was carried out using potassium hydroxide in the presence of phenolphthalein. Hydroxyl value of samples was determined according to equation 1 .

$H V=\frac{56.1 *\left(V_{2}-V_{1}\right) * C_{K O H}}{m}$

where $\mathrm{V}_{2}\left[\mathrm{~cm}^{3}\right]$ is the volume of titrant required for the titration of the blank solution, $\mathrm{V}_{1}\left[\mathrm{~cm}^{3}\right]$ is the volume of titrant required for the titration of a sample, $\mathrm{C}_{\mathrm{KOH}}[\mathrm{M}]$ is the molarity of the titrant, and $\mathrm{m}[\mathrm{g}]$ is the mass of the sample.

Table 1 Formulations of the obtained polyurethanes and polyurethane wood composites

\begin{tabular}{llll}
\hline Sample & Biopolyol used & NCO:OH ratio & $\begin{array}{l}\text { Wood } \\
\text { content } \\
{[\%]}\end{array}$ \\
\hline PPG 0.9 & PPG Polyol & $0.9: 1$ & $\mathrm{x}$ \\
PPG 1.0 & PPG Polyol & $1.0: 1$ & $\mathrm{x}$ \\
PPG 1.1 & PPG Polyol & $1.1: 1$ & $\mathrm{x}$ \\
PPG 1.2 & PPG Polyol & $1.2: 1$ & $\mathrm{x}$ \\
PG 0.9 & PG polyol & $0.9: 1$ & $\mathrm{x}$ \\
PG 1.0 & PG polyol & $1.0: 1$ & $\mathrm{x}$ \\
PG 1.1 & PG polyol & $1.1: 1$ & $\mathrm{x}$ \\
PG 1.2 & PG polyol & $1.2: 1$ & $\mathrm{x}$ \\
PU-WC 40 & PPG Polyol & $1.1: 1$ & 40 \\
PU-WC 50 & PPG Polyol & $1.1: 1$ & 50 \\
PU-WC 60 & PPG Polyol & $1.1: 1$ & 60 \\
PU-WC 70 & PPG Polyol & $1.1: 1$ & 70
\end{tabular}


For the determination of biomass conversion, the polyol sample $(1 \mathrm{~g})$ was diluted using ethanol and stirred using a magnetic stirrer for $1 \mathrm{~h}$. After that, the mixture was filtered through the filter paper under vacuum. The remaining solid fraction was dried at $105{ }^{\circ} \mathrm{C}$ to constant weight. This parameter was determined according to Eq. 2.

Biomass conversion $[\%]=100-\frac{m}{m_{0}} * 100$

where $\mathrm{m}[\mathrm{g}]$ is the weight of residual biomass and $\mathrm{m}_{\mathrm{o}}[\mathrm{g}]$ is the initial weight of biomass.

To determine the water absorption of polyurethane materials, water absorption test was carried out according to PN-EN ISO 62:2008. Three specimens for each composite were immersed in the distilled water at $23{ }^{\circ} \mathrm{C} \pm 2{ }^{\circ} \mathrm{C}$. The conditioned specimens were entirely immersed in a closed container. After taking out the specimens from the container, water on the surface was removed using a dry cloth. The 3.2 mm thick specimens $(\mathrm{n}=3)$ were weighed with an accuracy of up to $0.001 \mathrm{~g}$. The measurement was taken after 2, 24, 48, 96, 144, and $192 \mathrm{~h}$.

\subsubsection{Rheological properties}

To evaluate the viscosity and shear stress, the rheological properties of the obtained polyols were determined using $\mathrm{R} / \mathrm{S}$ Portable rheometer. Measurements were performed at a temperature of 30 and $50{ }^{\circ} \mathrm{C}$ and the shear rate varied from 1 to $200 \mathrm{~s}^{-1}$. Obtained results were analyzed using dedicated computer software.

\subsubsection{Chemical structure characterization}

The presence of specific chemical groups in the materials was determined using Fourier-transform infrared spectroscopy (FTIR). The test was performed using a Nicolet 8700 apparatus (Thermo Electron Corporation) equipped with a Snap-Gold State II. The analysis was performed at a resolution of $4 \mathrm{~cm}^{-1}$.

\subsubsection{Mechanical properties}

As the materials obtained are used for the production of boards, table tops, and laminates, which are subjected to bending or dynamic loads, flexural tests were performed in accordance with PN-EN ISO 14,125 using the universal testing machine Zwick/Roell $1000 \mathrm{~N}$. Tests were performed at a constant speed of $100 \mathrm{~mm} / \mathrm{min}$ until fracture. Rectangular samples $(\mathrm{n}=5)$ with dimensions $10 \times 1000 \times 3.2 \mathrm{~mm}$ were measured with a slide caliper with an accuracy of $0.01 \mathrm{~mm}$.

The impact strength was analysed using an Izod type hammer on beam-shaped samples $(\mathrm{n}=5)$ with dimensions $10 \times 1000 \times 3.2 \mathrm{~mm}$. The energy of the hammer was $5.5 \mathrm{~J}$.
The test was executed according to PN-EN ISO 180:2004. The hardness of the obtained composites was examined using the Shore D method. The test was executed according to PN-EN ISO 868:2005.

\subsubsection{Thermal properties}

To determine the thermal stability of polyurethanes and PUWCs, the thermogravimetric analysis (TGA) was performed using a NETZSCH TG 209 F3 apparatus (NETZSCHGruppe, Selb, Germany). The weight of the samples was $10 \pm 1 \mathrm{mg}$. Measurement was performed in a constant nitrogen flow in the temperature range from 30 to $800{ }^{\circ} \mathrm{C}$ and at a heating rate of $10{ }^{\circ} \mathrm{C} / \mathrm{min}$.

The dynamic mechanical analysis was performed using the DMA Q800 TA Instrument apparatus. Samples were analyzed in strain mode with a frequency of $1 \mathrm{~Hz}$. Measurements were taken in the temperature range from -120 to $140{ }^{\circ} \mathrm{C}$ with a heating rate of $4{ }^{\circ} \mathrm{C} / \mathrm{min}$. Beam-shaped samples with dimensions of $10 \mathrm{~mm} \times 40 \mathrm{~mm}$ were used.

\subsubsection{Morphological properties}

To determine the structure of the material, scanning electron microscopy (SEM) was used. This test was performed using SEM Quanta FEG 250. The samples were subjected to brittle cracking in liquid nitrogen, and to improve the conductivity, the samples were coated with a $10 \mathrm{~nm}$ gold layer.

\section{Results and discussion}

\subsection{Characterization of wood shavings}

Percentage content of each fraction and water content of wood shavings are shown in Table 2. The fraction of particle size was determined using a shaker with a sieve system. It can be seen that about $85 \%$ of all particles remained on the sieve size less than $0.6 \mathrm{~mm}$. This proves that the sample is thoroughly ground, therefore a high yield of the liquefaction

Table 2 Size of the wood shavings

\begin{tabular}{lcl}
\hline Mesh size $[\mathrm{mm}]$ & Particle content $[\%]$ & Water content $[\%]$ \\
\hline$<0.053$ & 3.43 & $7.06 \pm 0.21$ \\
$>0.053$ & 9.89 & \\
$>0.1$ & 18.83 & \\
$>0.2$ & 34.83 & \\
$>0.4$ & 17.82 & \\
$>0.6$ & 13.78 & \\
$>1$ & 1.21 & \\
$>2$ & 0.20 & \\
\hline
\end{tabular}


reaction can be expected. Measurements with a moisture analyzer showed that wood chips have approximately $7 \%$ water content, which may affect the quality of the liquefaction, because water molecules have a substantial impact on the disintegration of long biomass chains (Yao et al. 1995; Kosmela et al. 2019).

\subsection{Characterization of biopolyols}

The number of reactive hydroxyl groups in the structure of polyols impacts the quantity of urethane linkages, thus it has a considerable impact on the physical properties of the final polyurethane product. Among parameters such as acid number and viscosity, the hydroxyl number is one of the most important parameters to control during polyol production. In this process, the hydroxyl groups of glycerol/condensed glycerol/PEG 400, and the groups present in biomass (cellulose, lignin, and hemicelluloses) can react with each other (Hu and Li 2014; Kosmela et al. 2016). The hydroxyl value of polyol depends on many parameters such as: type of solvent, catalyst, reaction time, and temperature.

Figure 1 shows the changes of biomass conversion and hydroxyl values during the synthesis of biopolyols. The polyols are named according to the solvents used during synthesis: $100 \%$ PEG400 - PP polyol, 50\% PEG $400+50 \%$ glycerol - PPG polyol, and 100\% of glycerol - PG polyol.

It can be noticed that the total number of hydroxyl groups in PG polyol is decreasing and a noticeable drop of the hydroxyl number can be observed. The reaction was conducted with an excess of glycerol, leading to its condensation to polyglycerols and generation of water as byproducts (Hejna et al. 2018). Moreover, hydrolysis causes scission of biomass-derived long particles and generation of free hydroxyl groups. These two effects can be responsible for a momentary increase in hydroxyl value. During the first $4 \mathrm{~h}$

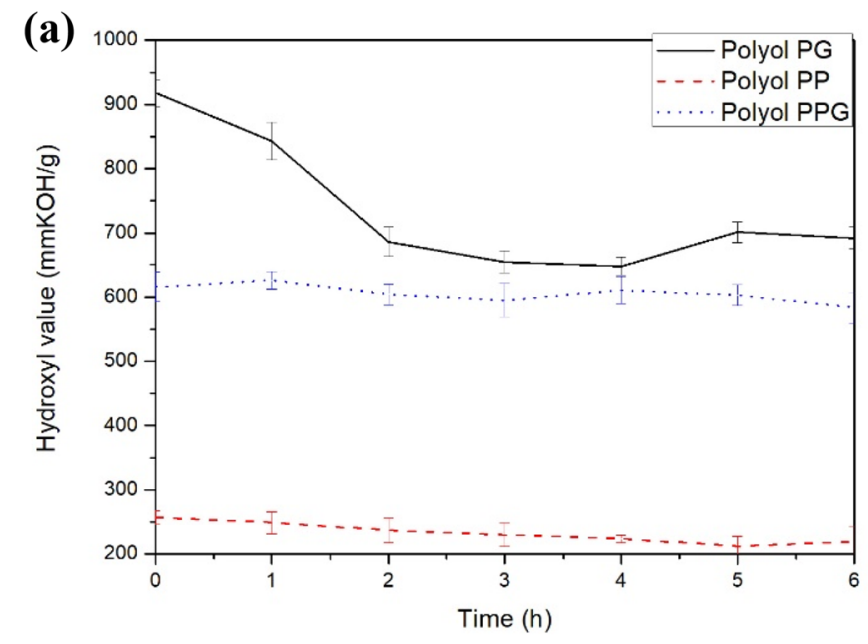

Fig. 1 Hydroxyl value $\mathbf{a}$ degree of biomass conversion and $\mathbf{b}$ of polyols of the reaction, it can be seen that the reactions of glycerol condensation and chain decomposition are predominant, and the by-product is properly collected. After $5 \mathrm{~h}$ of reaction, a temporary increase in the hydroxyl number can be noticed. This can be due to the re-polymerization of compounds generated during the biomass degradation. Analyzing the change in the hydroxyl number of the PPG polyol, a slight decrease in the hydroxyl number can be noticed. This may be evidence of glycerol condensation. However, the decrease in hydroxyl number is insignificant, which may indicate a reduction in the condensation reactions due to the addition of PEG400. The PP polyol has the lowest hydroxyl value. This is due to the lowest number of hydroxyl groups in the structure of this substance. This polyol shows the lowest dynamics of changes in the hydroxyl number, which may indicate the absence of additional solvent condensation reaction. The PG polyol sample has the highest value of this parameter. This is due to the presence of the largest amount of glycerol and its derivatives in the structure of the synthesized polyol. Analyzing the biomass conversion of the obtained polyols, it can be noticed that the conversion of over $90 \%$ was obtained fastest for the PG polyol (after about $2 \mathrm{~h}$ ). This may be due to the presence of water that favors the decomposition of the biomass chain. For comparison, the same biomass conversion was obtained for the PP and PPG samples after $4 \mathrm{~h}$. It can be concluded that glycerol is the most effective solvent in the liquefaction process, but it is associated with the additional reactions of condensation.

Viscosity describes the resistance of the fluid to flow. Fluids with lower viscosity flow easier, which from a technological point of view enables more efficient processing during the production of polyurethanes. The flow and viscosity curves of polyols at different temperatures are presented in Fig. 2. These results show that all polyols have a linear flow and can be described as a Newtonian fluid. The tests

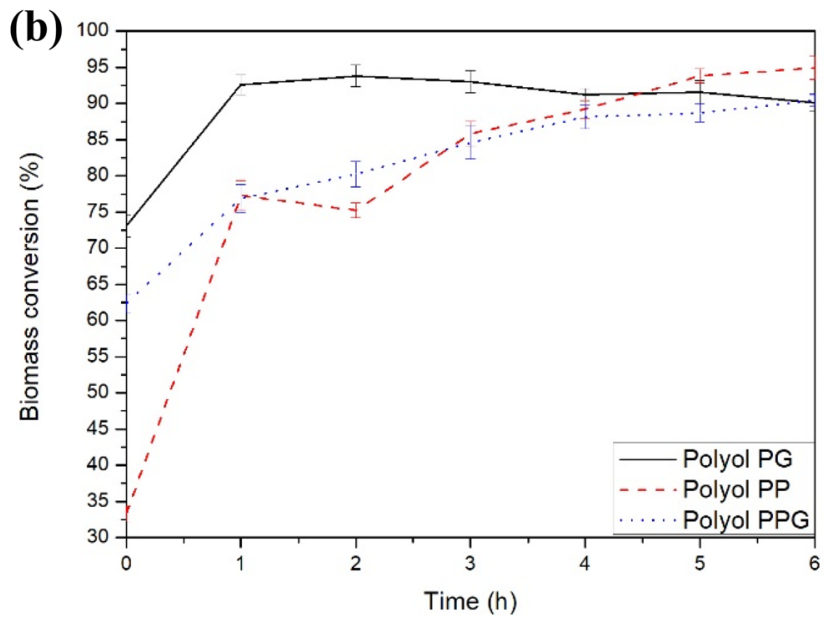


(a)

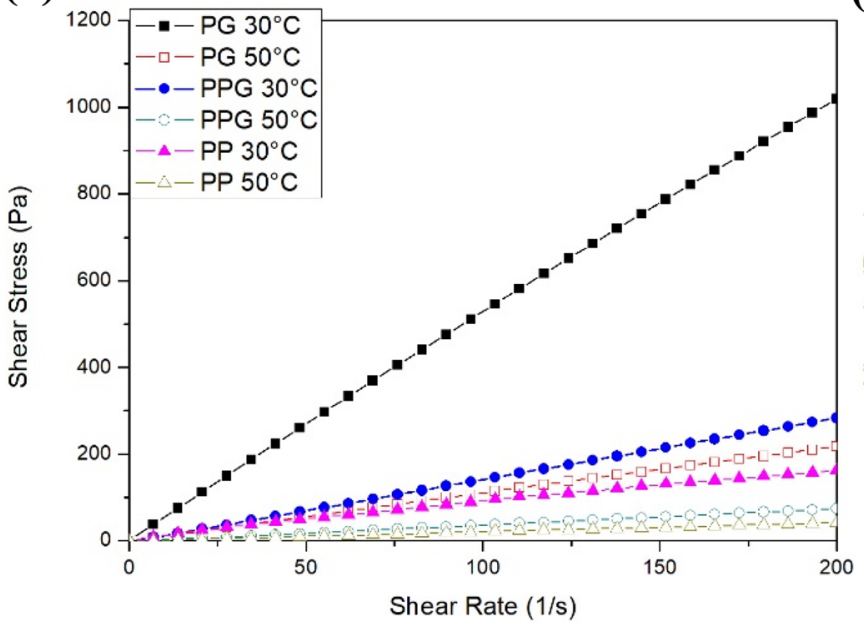

(b)

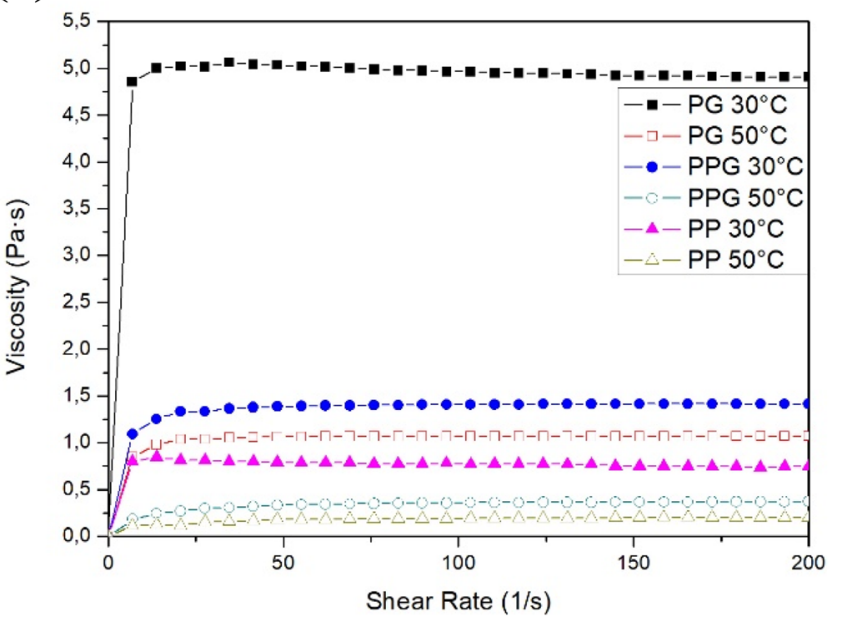

Fig. 2 Flow (a) and viscosity curves (b) of polyols at different temperatures

Table 3 Properties of the obtained polyols

\begin{tabular}{lllll}
\hline Sample & $\begin{array}{l}\text { Hydroxyl value } \\
\text { after neutraliza- } \\
\text { tion } \\
{[\mathrm{mg} \mathrm{KOH} / \mathrm{g}]}\end{array}$ & $\begin{array}{l}\text { Biomass } \\
\text { conversion } \\
{[\%]}\end{array}$ & $\begin{array}{l}\text { Viscosity } \\
{[\mathrm{Pa} \mathrm{s}]}\end{array}$ & $\begin{array}{l}\text { Water } \\
\text { content } \\
{[\%]}\end{array}$ \\
\hline PG polyol & $725 \pm 26$ & $90.6 \pm 1.6$ & 5.23 & 0.82 \\
PPG Polyol & $654 \pm 18$ & $91.1 \pm 0.8$ & 1.40 & 0.67 \\
PP polyol & $253 \pm 9$ & $94.2 \pm 1.1$ & 0.76 & 0.34 \\
\hline
\end{tabular}

revealed a strong correlation between viscosity and the type of solvent used. It can be noticed that the polyols containing glycerol have higher viscosity than polyol containing only PEG 400. Values of this parameter increase from $0.76 \mathrm{~Pa}$ s for PP polyol to 1.40 Pa s and 5.23 Pa s for PPG and PG polyols, respectively. Moreover, the tests revealed a strong correlation between the viscosity of polyols and the temperature of the measurement. This can be caused by an increase in macromolecules mobility and intermolecular space due to the increase in energy in the system. The properties of the obtained polyols are summarized in Table 3.

\subsection{Characterization of polyurethane materials}

\subsubsection{Mechanical properties of PU materials}

To obtain an appropriate material for the production of composites, samples with $\mathrm{NCO}: \mathrm{OH}$ ratios from $0.9: 1$ to $1.2: 1$ were obtained using previously synthesized polyols. This stage is crucial, as the properties of the polyurethanes significantly affect the mechanical properties and interactions between the phases of the composite. During this step, the processability of all polyols for the production of solid polyurethane materials was verified. Due to the high reactivity and a visible process of uncontrolled foaming of the material, the processing of PP polyol was abandoned. Table 4 shows a noticeable difference between the properties of PPG and PG materials. It was noticed that the PPG samples had higher elasticity and were less brittle (maximal deformation was over $200 \%$ higher for samples with the same $\mathrm{NCO} / \mathrm{OH}$ ratio) than PG samples. Better ability to transfer stresses meant that these samples had slightly higher impact strength.

Analyzing the influence of the isocyanate index on the mechanical properties of materials, it can be noticed that higher indexes lead to stiffer materials with higher flexural strength, hardness, and impact strength, but also with significantly lower deformability. Young`s modulus increased from $0.32 \mathrm{GPa}$ for PPG 0.9 to $1.27 \mathrm{GPa}$ for PPG 1.2, when flexural strength increased from 15.00 MPa for PPG 0.9 to $26.42 \mathrm{MPa}$ for PPG 1.1. This effect may be due to the reaction of excess isocyanate with itself and the formation of isocyanurate groups resulting in a higher stiffness and higher degree of cross-linking. At the same time, the maximal deformation decreased from $8.23 \%$ for PPG0.9 to $5.41 \%$ for PPG1.2. Similar relationship was noticed for samples from the PG series

\subsubsection{Chemical structure characterization}

The chemical structures of polyurethane materials were characterized by Fourier-transform infrared spectroscopy (FTIR). Figure 3 shows the FTIR spectra of manufactured materials. Broad adsorption peak at about $3330 \mathrm{~cm}^{-1}$ related to the symmetric and asymmetric stretching vibrations of $\mathrm{N}-\mathrm{H}$ can be noticed (Jiao et al. 2013). In-plane bending vibration of this group can be observed at around $1530 \mathrm{~cm}^{-1}$. The characteristic absorption bands correspond to $\mathrm{NCO}$ groups at $2270 \mathrm{~cm}^{-1}$. The presence of these bands may 
Table 4 Mechanical properties of polyurethanes with different $\mathrm{NCO} / \mathrm{OH}$ ratio

\begin{tabular}{|c|c|c|c|c|c|}
\hline Sample & $\begin{array}{l}\text { Flexural modulus } \\
\text { [GPa] }\end{array}$ & Flexural strength $[\mathrm{MPa}]$ & $\begin{array}{l}\text { Maximal deformation } \\
{[\%]}\end{array}$ & $\begin{array}{l}\text { Hardness } \\
{\left[{ }^{\circ} \mathrm{Sh} \mathrm{D}\right]}\end{array}$ & $\begin{array}{l}\text { Impact } \\
\text { strength }[\mathrm{kJ} / \\
\left.\mathrm{mm}^{2}\right]\end{array}$ \\
\hline PPG 0.9 & $0.32 \pm 0.08$ & $15.00 \pm 1.03$ & $8.23 \pm 0.76$ & $54.2 \pm 1.8$ & $2.38 \pm 0.48$ \\
\hline PPG 1.0 & $0.50 \pm 0.09$ & $18.02 \pm 0.42$ & $7.47 \pm 0.84$ & $55.4 \pm 2.0$ & $2.83 \pm 0.49$ \\
\hline PPG 1.1 & $0.94 \pm 0.09$ & $26.42 \pm 0.91$ & $5.96 \pm 0.68$ & $63.3 \pm 1.7$ & $3.12 \pm 0.59$ \\
\hline PPG 1.2 & $1.27 \pm 0.07$ & $19.70 \pm 1.18$ & $5.41 \pm 0.43$ & $61.0 \pm 1.2$ & $2.23 \pm 0.51$ \\
\hline PG 0.9 & $0.48 \pm 0.13$ & $15.29 \pm 0.49$ & $4.71 \pm 0.51$ & $53.4 \pm 1.9$ & $2.49 \pm 0.47$ \\
\hline PG 1.0 & $0.75 \pm 0.08$ & $17.99 \pm 1.06$ & $3.63 \pm 0.17$ & $61.1 \pm 1.3$ & $2.82 \pm 0.42$ \\
\hline PG 1.1 & $0.79 \pm 0.12$ & $24.21 \pm 0.71$ & $2.65 \pm 0.11$ & $63.1 \pm 1.9$ & $2.92 \pm 0.46$ \\
\hline PG 1.2 & $0.91 \pm 0.04$ & $21.67 \pm 1.14$ & $1.65 \pm 0.29$ & $61.0 \pm 1.6$ & $1.95 \pm 0.27$ \\
\hline
\end{tabular}

$P P G x x$ PG $\mathrm{xx}$ - sample with $\mathrm{xx}$ isocyanate index

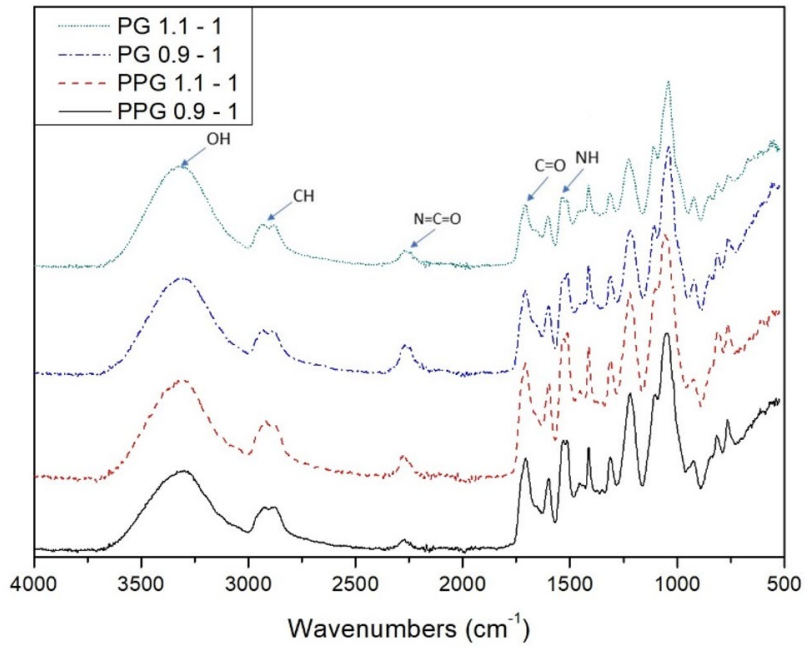

Fig. 3 FTIR spectra of materials

indicate an incomplete reaction of the components, the presence of $\mathrm{NCO} / \mathrm{OH}$ groups at the chain ends, or may be due to the excess isocyanate used in the manufacturing of PU (Jiao et al. 2013; Olszewski et al. 2021). C-N bond stretching in urethane groups can be noticed at $1200-1215 \mathrm{~cm}^{-1}$. Signals at about $1710 \mathrm{~cm}^{-1}$ can be associated with the stretching vibrations of $\mathrm{C}=\mathrm{O}$ bonds in the urethane linkage. The peaks at about 2970 and $2860 \mathrm{~cm}^{-1}$ are related to symmetric and asymmetric stretching vibrations in the methylene groups (C-H bonds). The presence of these groups confirmed that polyurethane material was obtained.

\subsubsection{Thermal properties}

To investigate the effect of the isocyanate index on the thermal properties of polyurethanes, thermogravimetric analysis was conducted. The weight loss (TG) and weight loss rate
(DTG) curves obtained for the synthesized materials are presented in Figs. 4 and 5. The results of these tests showed that all polyurethane materials degrade in four main steps. As can be seen in Table 5, the first stage of decomposition is due to the presence of volatile compounds in the structure of material. These compounds may come from unreacted low-molecular compounds during polyol synthesis. The temperature of this step $\left(\mathrm{T}_{\max 1}\right)$ ranges between 210 and $220{ }^{\circ} \mathrm{C}$ and is almost identical for PG and PPG. The second stage of decomposition at the maximum degradation temperature $\left(\mathrm{T}_{\max 2}\right.$ ) ranged from 285 to $336^{\circ} \mathrm{C}$ and can be correlated with the dissociation of urethane linkages. This decomposition leads to the formation of isocyanates, polyols, amines, and carbon dioxide (Jiao et al. 2013; Yeoh et al. 2020). It can be noticed that the temperature of this step is significantly higher for the PPG materials $\left(330{ }^{\circ} \mathrm{C}\right)$ in comparison to the PG $\left(285^{\circ} \mathrm{C}\right)$.

The third stage of decomposition ranging from 383 to $406{ }^{\circ} \mathrm{C}\left(\mathrm{T}_{\max 3}\right)$ is due to the decomposition of the polyurethane soft segments. This decomposition may be connected to the degradation of soft segments formed by the biopolyol such as poly (ethylene glycol) segments or linkages in glycerol derivates in the polyurethane soft segments (Kosmela et al. 2020; Szlachta et al. 2021). Once more, the degradation temperature is significantly higher for the PPG materials $\left(400{ }^{\circ} \mathrm{C}\right)$ in comparison to the PG $\left(380^{\circ} \mathrm{C}\right)$. One possible explanation for this decrease is that soft segments composed of PEG 400 have higher thermal stability than segments composed of glycerol and glycerol derivates. The last step of the degradation arises in a range $\mathrm{T}_{\operatorname{maxIV}}=460-470{ }^{\circ} \mathrm{C}$ and may result from the thermolysis of organic products generated during previous degradation stages (Kosmela et al. 2017). No significant differences were found in the fourth degradation for both materials

For PG samples, the 5\% mass loss $\left(\mathrm{T}_{5 \%}\right)$ was observed at temperatures of about $195{ }^{\circ} \mathrm{C}$ and at $213{ }^{\circ} \mathrm{C}$ for PPG materials. Increase of isocyanate index from 0.9 to 1.1 led to the 
(a)

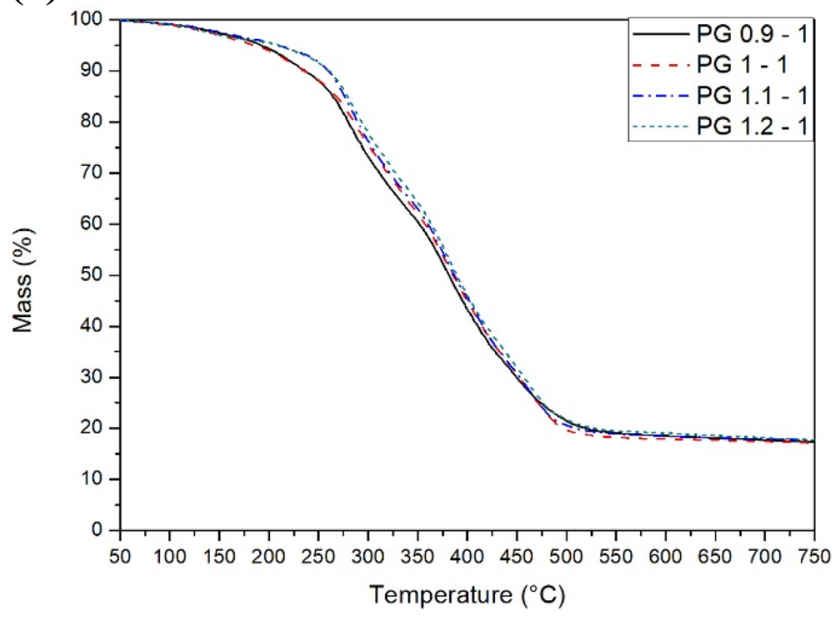

(b)

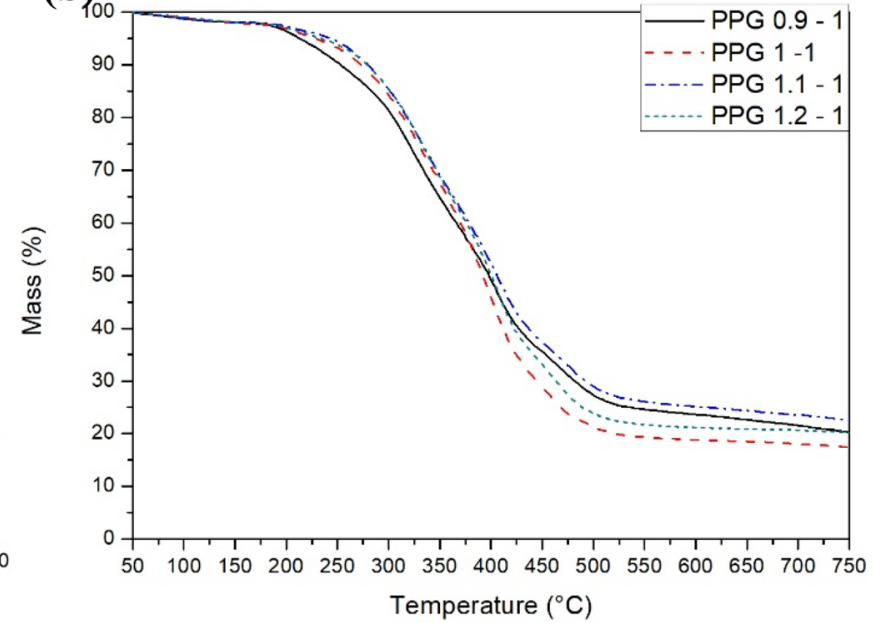

Fig. 4 TGA curves of polyurethanes a PG samples, b PPG samples

Table 5 Results of thermogravimetric analysis of polyurethanes

\begin{tabular}{|c|c|c|c|c|c|c|c|c|}
\hline \multirow[t]{2}{*}{ Sample } & \multicolumn{3}{|c|}{$\begin{array}{l}\text { Different } \% \text { mass loss in } \\
\text { temperature }\left[{ }^{\circ} \mathrm{C}\right]\end{array}$} & \multirow[t]{2}{*}{$\begin{array}{l}\mathrm{T}_{\max 1} \\
{\left[{ }^{\circ} \mathrm{C}\right]}\end{array}$} & \multirow[t]{2}{*}{$\begin{array}{l}\mathrm{T}_{\max 2} \\
{\left[{ }^{\circ} \mathrm{C}\right]}\end{array}$} & \multirow[t]{2}{*}{$\begin{array}{l}\mathrm{T}_{\max 3} \\
{\left[{ }^{\circ} \mathrm{C}\right]}\end{array}$} & \multirow[t]{2}{*}{$\begin{array}{l}\mathrm{T}_{\max 4} \\
{\left[{ }^{\circ} \mathrm{C}\right]}\end{array}$} & \multirow[t]{2}{*}{$\begin{array}{l}\text { Char residue } \\
\text { after test [\%] }\end{array}$} \\
\hline & $5 \%$ & $10 \%$ & $50 \%$ & & & & & \\
\hline PG 0.9 & 193 & 236 & 381 & 219 & 280 & 383 & 462 & 17.0 \\
\hline PG 1.0 & 196 & 237 & 386 & 220 & 283 & 382 & 460 & 17.0 \\
\hline PG 1.1 & 210 & 260 & 387 & 216 & 278 & 378 & 461 & 17.0 \\
\hline PG 1.2 & 211 & 260 & 389 & 221 & 284 & 380 & 459 & 17.5 \\
\hline PPG 0.9 & 213 & 254 & 398 & 213 & 325 & 404 & 471 & 19.9 \\
\hline PPG 1.0 & 229 & 274 & 392 & 218 & 336 & 403 & 452 & 17.2 \\
\hline PPG 1.1 & 243 & 280 & 406 & 204 & 335 & 407 & 472 & 22.4 \\
\hline PPG 1.2 & 234 & 280 & 401 & 214 & 336 & 406 & 455 & 20.1 \\
\hline
\end{tabular}

(a)

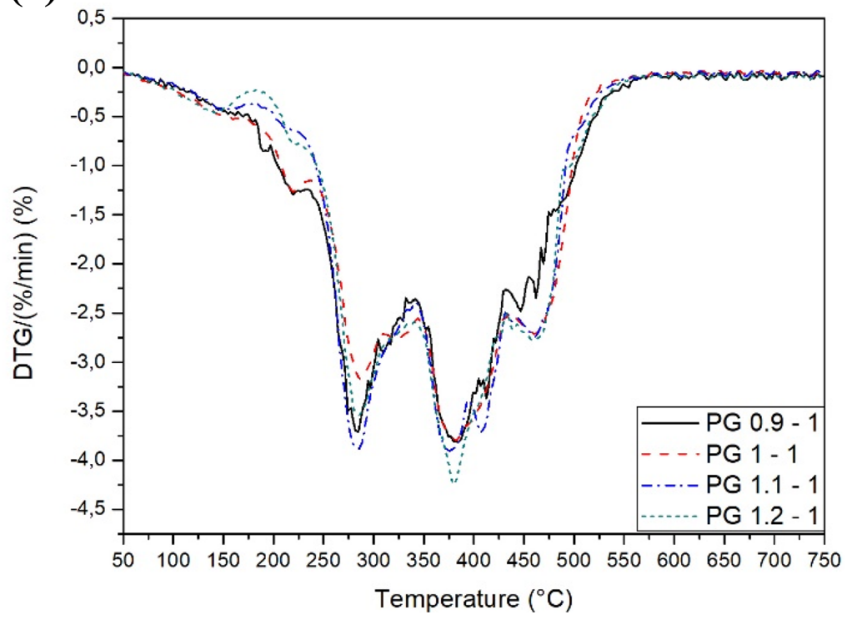

(b)

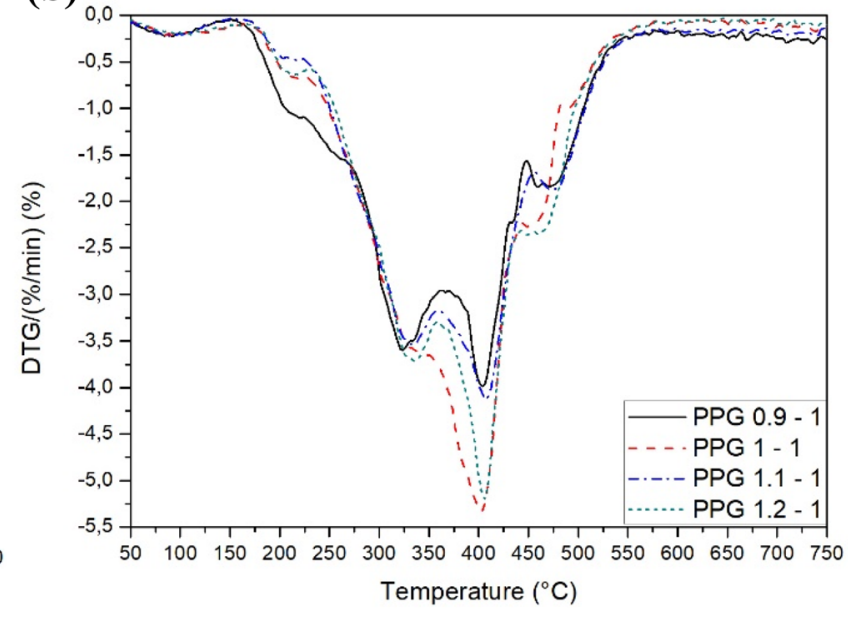

Fig. 5 DTG curves of polyurethanes a PG samples, b PPG samples 
increase of this temperature to $210{ }^{\circ} \mathrm{C}$ for PG and $243{ }^{\circ} \mathrm{C}$ for PPG. Increase in $\mathrm{T}_{5 \%}$ for both types of materials can be explained by obtaining more thermally stable isocyanurate bonds in the structure. Moreover, a slight increase in the decomposition temperature of polyurethane with higher $\mathrm{NCO} / \mathrm{OH}$ ratio at $50 \%$ mass loss $\left(\mathrm{T}_{50 \%}\right)$ was observed. Materials with the ratio of $\mathrm{NCO} / \mathrm{OH}=0.9$ (the highest deformability) and 1.1 (the highest flexural and impact strength) were found to be the most useful materials in the

(a)

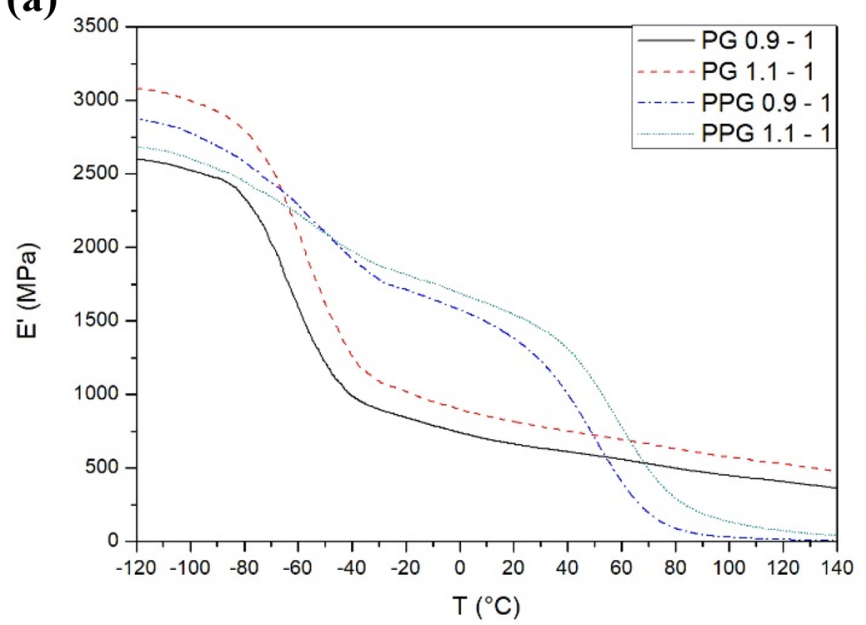

manufacturing of composites, therefore they were analyzed in more detail.

Figure 6a shows the storage modulus of polyurethanes. Analyzing this parameter, it can be noticed that the storage modulus increases with the increase in isocyanate index in a wide temperature range. As can be seen in Table 6, PPG sample storage modulus in $20{ }^{\circ} \mathrm{C}$ increased from 1381 to $1545 \mathrm{MPa}$ when the isocyanate index was increased from 0.9 to 1.1. Similar effect was observed for PG and this value increased from 664 to $814 \mathrm{MPa}$. This effect may be caused

(b)

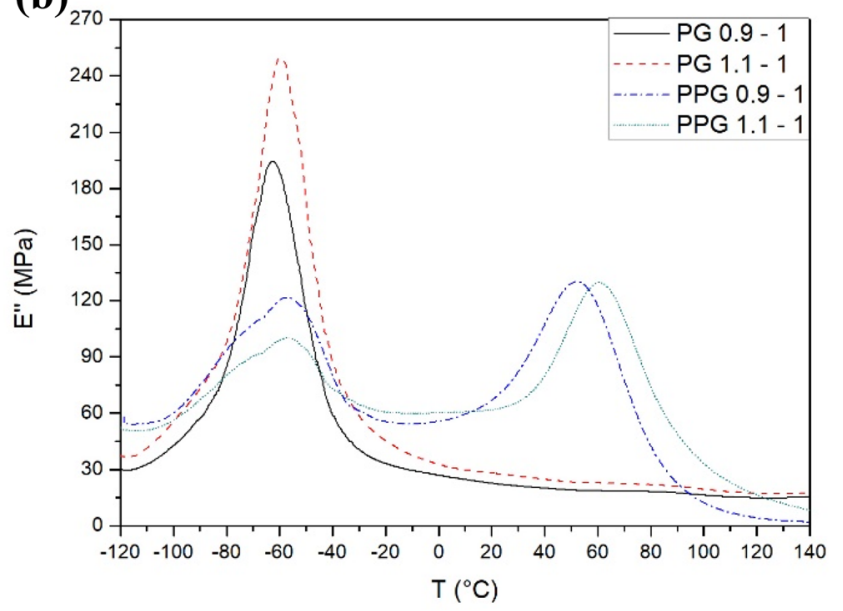

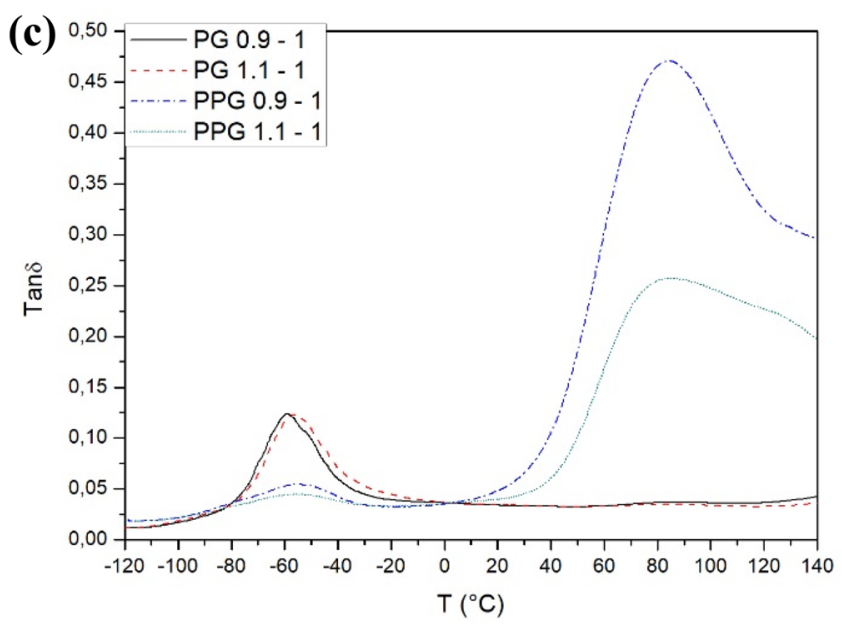

Fig. 6 DMA curves of polyurethane materials, a storage modulus; $\mathbf{b}$ loss modulus; $\mathbf{c}$ damping factor

Table 6 Storage modulus at different temperatures and glass transition (Tg) of soft segments

\begin{tabular}{lccccc}
\hline Sample & $\begin{array}{l}\mathrm{E}^{\prime}{ }_{20}^{\circ} \mathrm{C} \\
{[\mathrm{MPa}]}\end{array}$ & $\mathrm{E}_{60{ }^{\circ} \mathrm{C}}[\mathrm{MPa}]$ & $\mathrm{E}^{\prime}{ }_{100{ }^{\circ} \mathrm{C}}[\mathrm{MPa}]$ & $\begin{array}{l}\mathrm{I} \mathrm{Segment}_{\mathrm{T}} \\
{\left[{ }^{\circ} \mathrm{C}\right]}\end{array}$ & $\begin{array}{l}\text { II Seg- } \\
\text { ment } \\
{\left[{ }^{\circ} \mathrm{C}\right]}\end{array}$ \\
\hline PG 0.9 & 664 & 556 & 447 & -62 & - \\
PG 1.1 & 814 & 692 & 572 & -58 & - \\
PPG 0.9 & 1381 & 412 & 28 & -56 & 51 \\
PPG 1.1 & 1545 & 778 & 131 & -56 & 60 \\
\hline
\end{tabular}


by the increase in the amount of rigid segment with the increase in the amount of isocyanate. At temperatures up to about $50{ }^{\circ} \mathrm{C}$, the PPG samples show a higher storage modulus than the PG. This may be due to the greater ability of the elastic segments of PEG400 to store mechanical energy during deformation. Above this temperature, PG samples have higher storage modulus. This may be due to the higher crosslinking density of PG samples, as they contain a greater amount of glycerol and its derivatives formed during the reaction, and as a result, greater functionality.

The loss modulus curves, presented in Fig. 6b, were used to determine the impact of isocyanate index on the glass transition temperature of the polyurethanes. It can be concluded that the first peak is the glass transition temperature of the chains of glycerol and its derivatives and the second peak is the glass transition temperature of a long and flexible PEG 400 chain. No noteworthy differences were found between the glass transition (Tg) of I soft segments, which may be composed of long and flexible chains of PEG 400. However, a noticeable correlation between the isocyanate index and glass transition of II soft segments, which can be composed of glycerol and glycerol derivates, can be noticed. This effect can be connected to the increase in the number of rigid segments in the PPG matrix structure and the restriction of chain mobility. Glass transition temperature increased from 51 to $60{ }^{\circ} \mathrm{C}$ for PPG0.9 and PPG1.1, respectively. The results are in line with other studies (Kim et al. 2008; Ivdre et al. 2020)

Figure $6 \mathrm{c}$ shows the variation of loss factor. This parameter is the ratio of loss modulus to storage modulus and it gives information about the damping properties of the material and measures the degree of mobility of molecules (Khan et al. 2020). It can be noticed that there is no significant change of damping factor of PG samples with modification of isocyanate index. Other relations can be seen for PPG samples where a noticeable drop of the damping factor can be seen. These results show that the efficiency of stress transfer increases with the isocyanate index for PPG samples

Due to the obtained results, the PPG 1.1 sample was selected for composites manufacturing. This choice is due to the combination of relatively high deformability, high mechanical properties, and the highest thermal stability. Moreover, the excess of isocyanate groups in the formula used will be able to react with $\mathrm{OH}$ groups present in the structure of the filler used. This effect will lead to an improvement in the interaction between both phases of the composite and to obtain composites with better mechanical properties.

\subsection{Characterization of polyurethane wood composites (PU-WC)}

\subsubsection{Mechanical properties of PU materials}

Mechanical properties of polyurethane wood composites are shown in Table 7. The table summarizes such properties as Young`s modulus, flexural strength, maximal deformation, hardness, and impact strength. These results show a significant improvement of Young`s modulus, flexural strength, hardness, and impact strength with the addition of a filler up to $60 \%$. On the other hand, the maximal deformation of materials decreased from $5.41 \%$ to only $1.67 \%$ for PU-WC 70. Additionally, the sample with $60 \%$ filler addition is characterized by the best mechanical properties. Flexural strength has been improved from 26.42 $\mathrm{MPa}$ (unfilled material) to $49.60 \mathrm{MPa}$ and Young`s modulus increased from 0.94 to $2.86 \mathrm{GPa}$. The obtained results may prove the reinforcing effect of the filler as well as the good compatibility of the filler with the matrix. These results are consistent with other research (Ge et al. 2006; Jain and Gupta 2018). The incorporation of higher amount of wood filler resulted in a noticeable decrease in all mechanical properties. This effect can be related to the agglomerates and free spaces between filler particles limiting the load transfer between the polymeric matrix and the filler. Moreover, this phenomenon can lead to the initiation and propagation of cracks, which reduce the mechanical properties of the obtained composites (Kasprzyk et al. 2020). Although this study showed significant improvement of mechanical properties, other research shows a greater increase in flexural strength and modulus

Table 7 Mechanical properties of polyurethane wood composites

\begin{tabular}{|c|c|c|c|c|c|}
\hline Sample & $\begin{array}{l}\text { Flexural modulus } \\
\text { [GPa] }\end{array}$ & Flexural strength $[\mathrm{MPa}]$ & $\begin{array}{l}\text { Maximal deforma- } \\
\text { tion [\%] }\end{array}$ & Hardness $\left[{ }^{\circ} \mathrm{Sh} \mathrm{D}\right]$ & $\begin{array}{l}\text { Impact } \\
\text { strength }[\mathrm{kJ} / \\
\left.\mathrm{mm}^{2}\right]\end{array}$ \\
\hline PPG 1.1 & $0.94 \pm 0.09$ & $26.42 \pm 0.91$ & $5.96 \pm 0.68$ & $63.3 \pm 1.7$ & $3.12 \pm 0.59$ \\
\hline PU-WC 40 & $2.27 \pm 0.15$ & $43.53 \pm 1.45$ & $2.01 \pm 0.06$ & $82.2 \pm 1.4$ & $4.97 \pm 0.73$ \\
\hline PU-WC 50 & $2.49 \pm 0.21$ & $45.68 \pm 1.30$ & $1.82 \pm 0.22$ & $84.1 \pm 1.7$ & $4.61 \pm 0.40$ \\
\hline PU-WC 60 & $2.86 \pm 0.14$ & $49.60 \pm 1.02$ & $1.77 \pm 0.11$ & $84.4 \pm 1.4$ & $4.83 \pm 0.94$ \\
\hline PU-WC 70 & $2.23 \pm 0.27$ & $44.50 \pm 1.00$ & $1.67 \pm 0.07$ & $80.9 \pm 2.7$ & $4.38 \pm 1.25$ \\
\hline
\end{tabular}

PU-WC xx-sample with $\mathrm{xx} \%$ wood content 
with the addition of glass and carbon fiber (Olszewski et al. 2021). This can be due to the higher mechanical properties of the fibers used. An almost equally large improvement in mechanical properties has been observed in hybrid composites containing $10 \%$ of glass fiber and $5 \%$ of sisal fiber (Olszewski et al. 2020). These results need to be interpreted with caution, because the compared materials were made of a different type of polyol.

\subsubsection{Water absorption test}

Figure 7 shows the change of water absorption of samples during immersion in distilled water. This figure suggests that all samples reached the maximum saturation weight after $96 \mathrm{~h}$ and water adsorption increases with the addition of wooden filler. The greatest increase in this parameter (in comparison to the other samples) can be observed for the PU-WC 70. After $96 \mathrm{~h}$, the water adsorption increased from $8 \%$ for PPG 1.1 to $22 \%$ for the PU-WC 70 sample. It may be due to the higher amount of wood filler, which cannot be completely covered by bio-based polyurethane material. This phenomenon is more noticeable for composites with higher filler addition. This may be due to the characteristics of wood, which can contain a lot of free hydroxyl $(\mathrm{OH})$

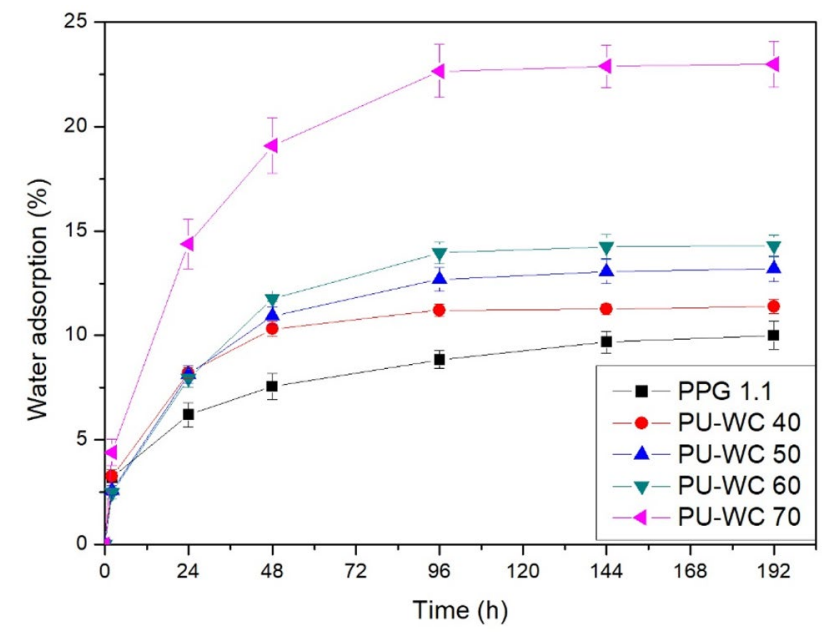

Fig. 7 Water adsorption of PU-WC groups of cellulose. In combination with water, these groups can form hydrogen bonds as confirmed by Barbos et al. (2020). Cellulose and hemicelluloses, which are present in wood, are mostly responsible for the high thickness swelling and water absorption of natural fibers, since they contain numerous accessible hydroxyl groups (Ayrilmis et al. 2017).

\subsubsection{Thermal properties}

Table 8 shows E' value at different temperatures and Fig. 8 shows DMA curves of wood-polymer composites. It was found that the addition of filler increases the storage modulus of composites in a wide range of temperatures. This parameter increases with the addition of filler up to $50 \%$. Above $50 \%$, no further increase occurs. As can be seen, the storage modulus at $20{ }^{\circ} \mathrm{C}$ increased from $1375 \mathrm{MPa}$ (neat bio-PU) to $4775 \mathrm{MPa}$ for PU-WC 50. The observed increase in the storage module is almost $250 \%$ in comparison to PPG1.1. This proves the reinforcing effect of the filler and it is consistent with the outcome of the flexural testing (Ayrilmis et al. 2017). Similar results were obtained in the experiment by Olszewski et al. (2021). Interestingly, storage modulus of PU-WC 60 decreases slower than the modulus of the sample with $60 \%$ addition of glass fiber. This may be due to better adhesion of the filler to the matrix or higher filler effectiveness. Moreover, the glass transition temperature of the I segment does not differ significantly from that obtained for materials with glass fiber. However, the glass transition temperature of the second segments increased significantly. This may be due to the increase in the cross-link density of the material due to the reaction of the isocyanate with the active $\mathrm{OH}$ groups of the filler.

It was observed that the addition of wood shavings does not affect significantly the glass transition temperature of I soft segments, but $T_{g}$ of II soft segments increases with the filler addition. The observed increase in this parameter could be interpreted as a decrease in the polymer chain mobility in the matrix due to the addition of filler (Olszewski et al. 2021). This can be due to the presence of an interaction between bio-based polyurethane and wooden filler or by reactions between filler and material, leading to higher
Table 8 Storage modulus at different temperatures and glass transition $\left(\mathrm{T}_{\mathrm{g}}\right)$ of soft segments

\begin{tabular}{lccccc}
\hline Sample & $\mathrm{E}_{20{ }^{\circ} \mathrm{C}}[\mathrm{MPa}]$ & $\mathrm{E}_{60{ }^{\circ} \mathrm{C}}^{\prime}[\mathrm{MPa}]$ & $\mathrm{E}^{\prime}{ }_{100{ }^{\circ} \mathrm{C}}[\mathrm{MPa}]$ & $\begin{array}{l}\text { I Segment } \mathrm{T}_{\mathrm{g}} \\
{\left[{ }^{\circ} \mathrm{C}\right]}\end{array}$ & $\begin{array}{l}\text { II Seg- } \\
\mathrm{ment}_{\mathrm{g}} \\
{\left[{ }^{\circ} \mathrm{C}\right]}\end{array}$ \\
\hline PPG 1.1 & 1545 & 778 & 131 & -56 & 60 \\
PU-WC 40 & 3675 & 2717 & 1330 & -63 & 74 \\
PU-WC 50 & 4775 & 3439 & 1580 & -58 & 75 \\
PU-WC 60 & 4483 & 3475 & 1978 & -58 & 78 \\
PU-WC 70 & 4541 & 3577 & 1876 & -59 & 76 \\
\hline
\end{tabular}


(a)

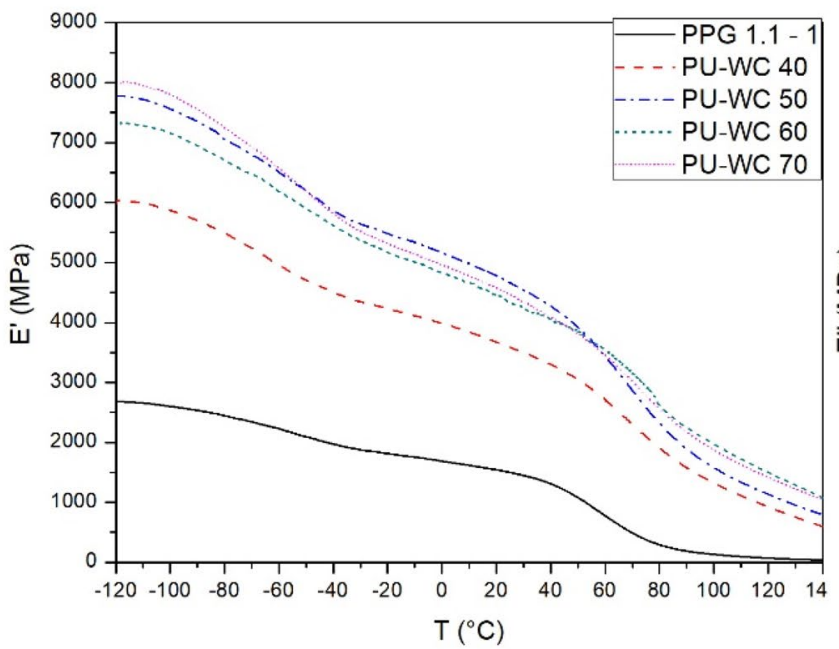

(b)

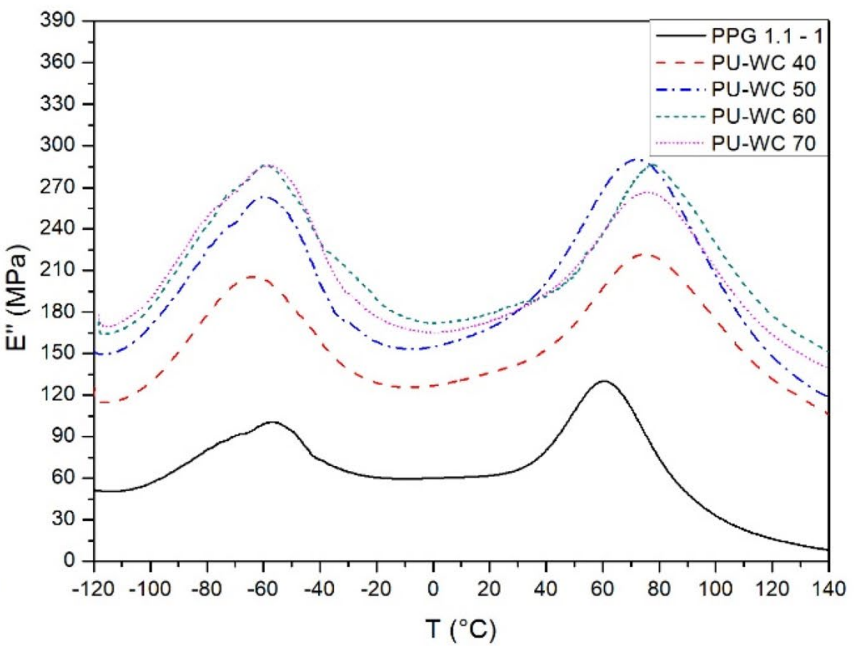

(c)

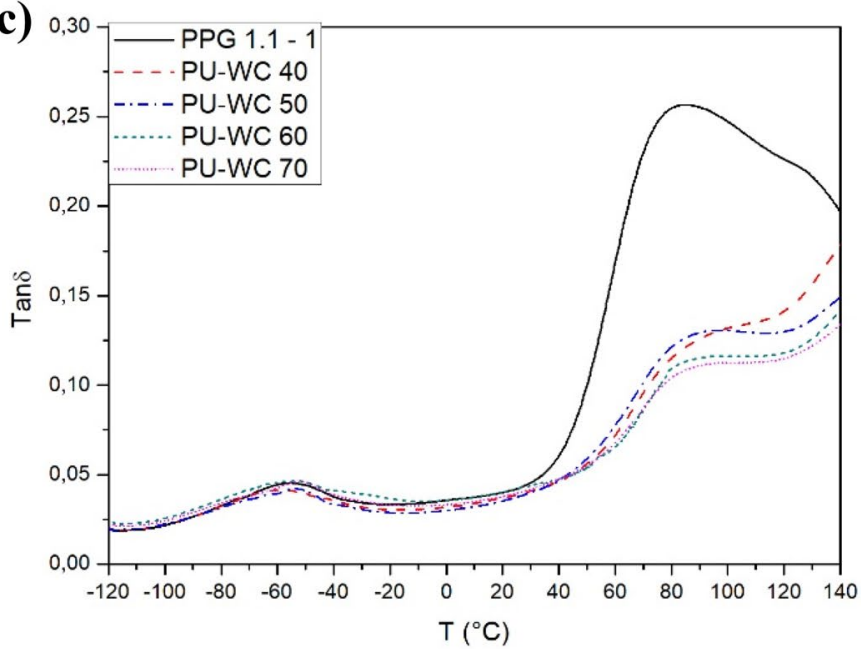

Fig. 8 DMA curves of wood-polymer composites, a storage modulus; $\mathbf{b}$ loss modulus; $\mathbf{c}$ damping factor

crosslinking density. This effect is in line with Ge et al. (2006) and Vimalanathan et al. (2016)

Damping factor $(\operatorname{Tan} \delta$ ) of composites highly depends upon the filler-matrix interface. This parameter shows the quality of the interactions between phases, damping, and load bearing capacity of the composites (Ge et al. 2006). The lowest peak of Tan $\delta$ curve can be noticed for samples coded PU-WC 60 and PU-WC 70. These results suggest that both samples have a good load bearing capacity. Furthermore, it can be concluded that the drop of this parameter is correlated with the intensified interactions between phases in all bio-based composites and the effective reinforcement by wooden filler.

The weight loss (TG) and weight loss rate (DTG) curves obtained for wood shavings and bio-based PU-WC are presented in Fig. 9. For wood shavings (WS), it can be noted that the degradation starts at around $200{ }^{\circ} \mathrm{C}$. Maximal degradation temperature of wood shavings was observed at $\mathrm{T}_{\max }=$
$363{ }^{\circ} \mathrm{C}$. This peak is related to the simultaneous degradation of wood components such as cellulose, hemicelluloses, and lignin (Yang et al. 2006; Poletto et al. 2012). The results of these tests showed that the obtained materials degraded in one main step. This peak corresponds to the dissociation of urethane linkages in bio-polyurethane $\left(\mathrm{T}_{\text {maxII }}\right)$ and degradation of wood at similar temperatures, what is confirmed by $\mathrm{T}_{5 \%}$ and $\mathrm{T}_{10 \%}$ values for both samples. The degradation of the filler hides the remaining peaks ( $\left.\mathrm{T}_{\max }, \mathrm{T}_{\max I I I}, \mathrm{~T}_{\operatorname{maxIV}}\right)$ that resulted from the degradation of the polyurethane. It is due to the reduction in the amount of bio-polyurethane in the sample. As can be seen in Table 9, the addition of filler may lead to the deterioration of the thermal stability of materials. $\mathrm{T}_{5 \%}$ decreased from $244^{\circ} \mathrm{C}$ for PPG1.1 to $225^{\circ} \mathrm{C}$ for PU-WC 70. This may be due to high water absorption of wood inside the composites and the slow water loss from the entire sample volume during the test. The same effect was observed for $\mathrm{T}_{10 \%}$. An increase in char residue after the test 
(a)

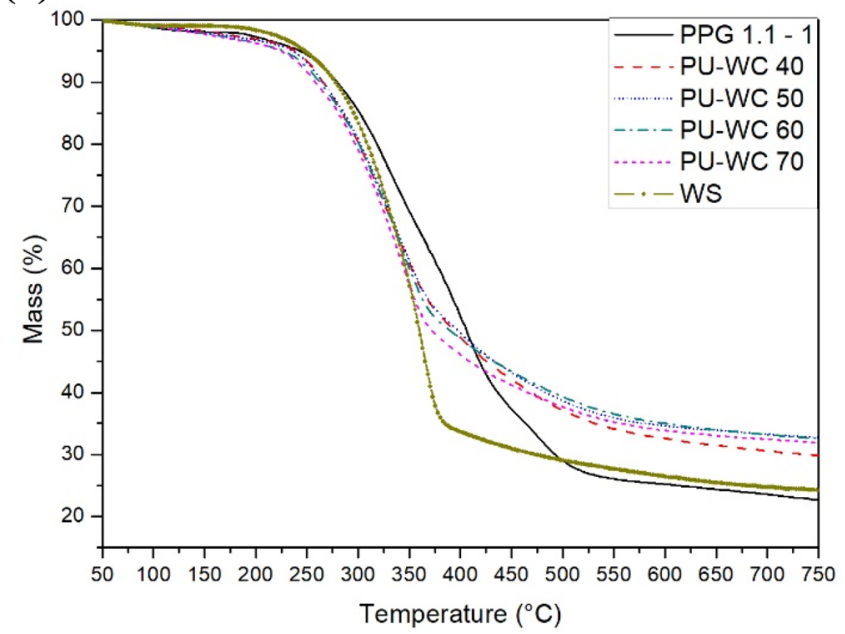

(b)

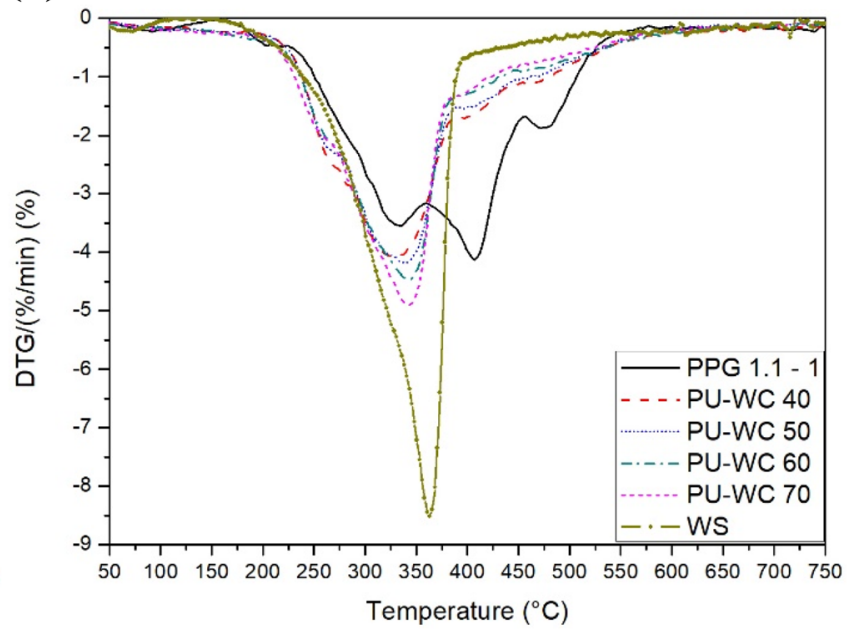

Fig. 9 DTG curves of wood-polymer composites

Table 9 Results of thermogravimetric analysis of wood-polymer composites

\begin{tabular}{llllllc}
\hline Sample & \multicolumn{3}{l}{$\begin{array}{l}\text { Different\% mass loss in tempera- } \\
\left.\text { ture [ }{ }^{\circ} \mathrm{C}\right]\end{array}$} & $\mathrm{T}_{\text {maxII }}\left[{ }^{\circ} \mathrm{C}\right]$ & $\mathrm{T}_{\text {maxIII }}\left[{ }^{\circ} \mathrm{C}\right]$ & $\begin{array}{c}\text { Char residue } \\
\text { after test [\%] }\end{array}$ \\
\cline { 2 - 4 } & $5 \%$ & $10 \%$ & $50 \%$ & & & \\
\hline PPG 1.1 & 243 & 280 & 406 & 336 & 407 & 22.4 \\
PU-WC 40 & 239 & 266 & 394 & 331 & - & 29.4 \\
PU-WC 50 & 236 & 266 & 397 & 339 & - & 32.6 \\
PU-WC 60 & 227 & 263 & 390 & 343 & - & 32.4 \\
PU-WC 70 & 225 & 260 & 372 & 344 & - & 23.8 \\
WS & 248 & 278 & 360 & 363 & - & \\
\hline
\end{tabular}

was noted. This may be the result of the reaction of wood and polyurethane decomposition products, and the formation of char or compounds, which may degrade at higher temperatures. The tests revealed a significant difference between $\mathrm{T}_{50 \%}$ of matrix and composites. This can be due to the almost complete degradation of wood at this temperature. These results show a significant relationship between the thermal stability of materials and the type of filler. $\mathrm{T}_{5 \%}$ of PU-WC 60 is almost $70{ }^{\circ} \mathrm{C}$ lower than for samples with high glass fiber content (Olszewski et al. 2021).

\subsubsection{Morphological properties}

To obtain information regarding the morphology of the materials, SEM micrographs using scanning electron microscope were taken. Figure 10 shows the micrograph of PPG 1.1 (sample without filler addition). During the analysis of unfilled material, a number of defects can be found. The presented micrograph shows local foaming of the sample. This is caused by $\mathrm{CO}_{2}$ generation during the reaction of isocyanate and residual water, remaining after drying the polyol. The voids formed act as internal and external notches (if foaming on the sample surface has occurred), reduce cross-sectional area of the sample, cause local stress concentration, and may lead to crack propagation through defects. This effect leads to a significant reduction in the flexural and impact strength and deformability of the material. Moreover, few crack propagation sites can be noticed, which may indicate a brittle course of cracking.

Figures 11, 12 and 13 show micrographs of fractured samples of PU-WC with increasing content of wood shavings. Analyzing the surface of the fracture, it can be noticed that the fracture of the composite occurred not only across the polyurethane matrix but also the longitudinal and transverse fracture of the filler can be noticed. There is no clear evidence of wood particle pull-out. These phenomena prove the high adhesion between the filler and the polyurethane. This can be due to the presence of reactive $\mathrm{OH}$ groups on the surface of the filler, which may react with the excess isocyanate. Moreover, the developed surface of the filler may provide a high surface area of interaction between the 

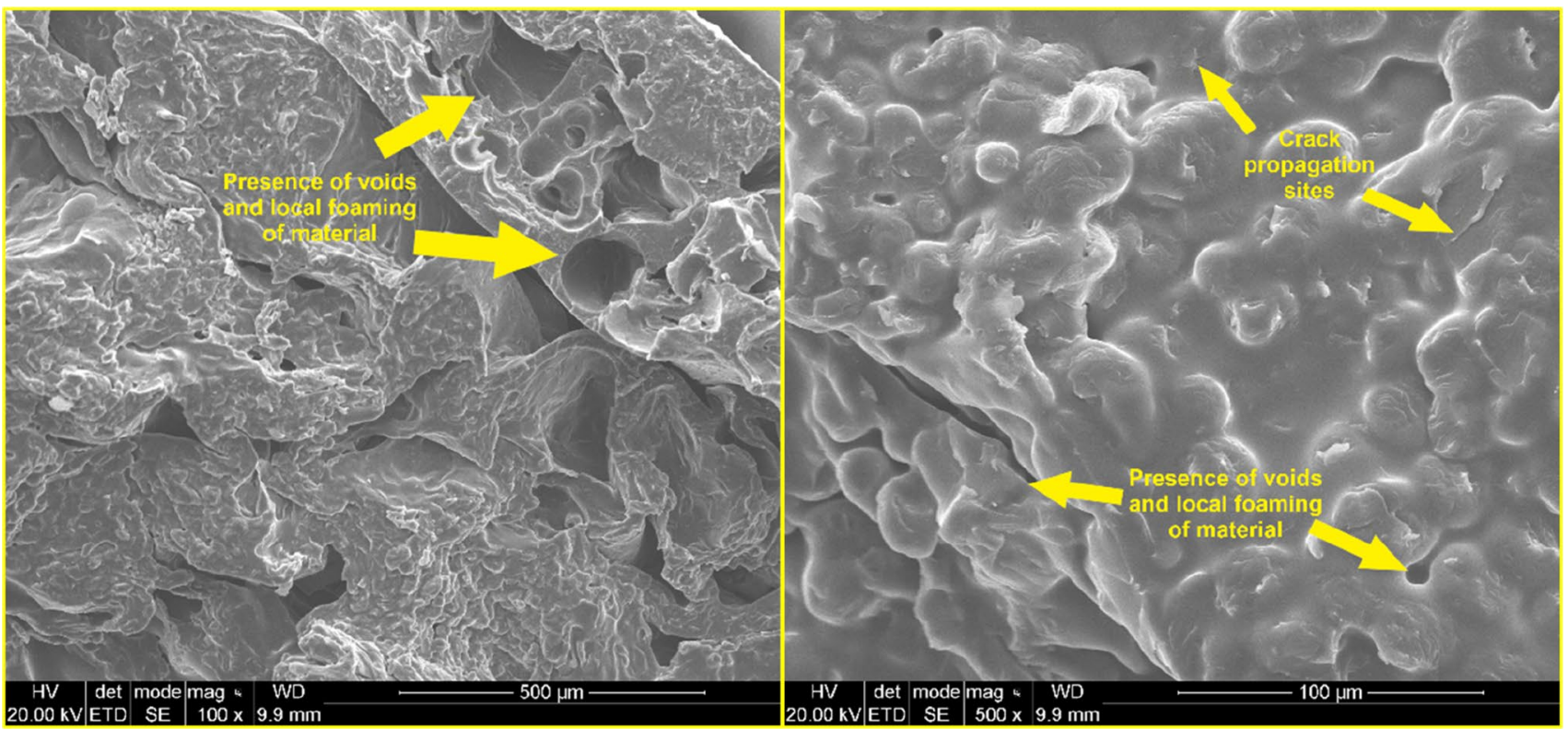

Fig. 10 SEM images of PPG 1.1

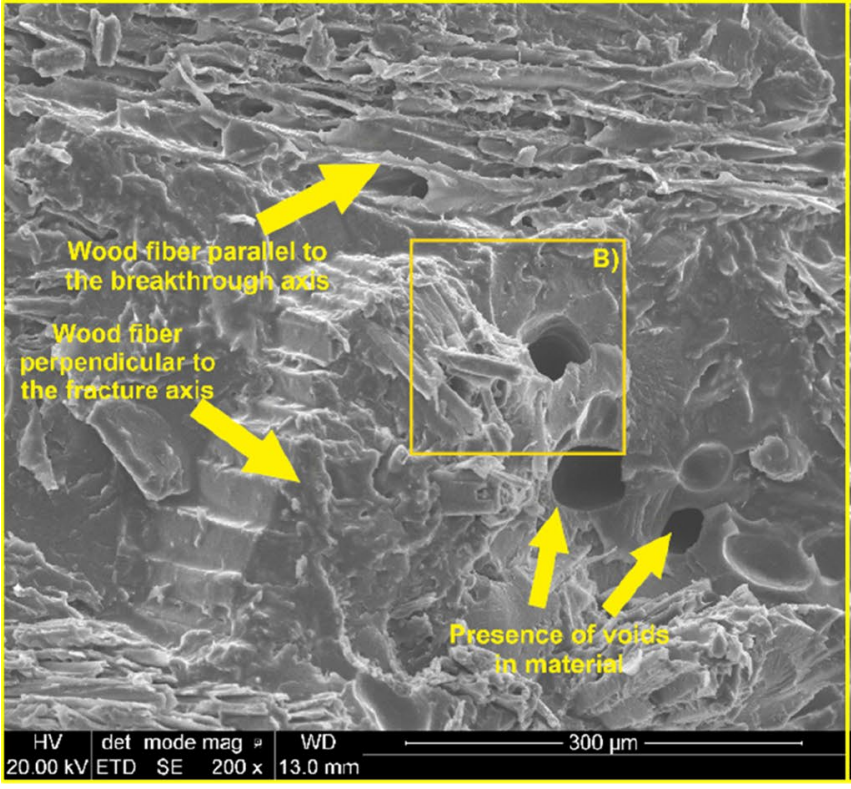

Fig. 11 SEM images of sample coded PU-WC 40

phases of the composite, which additionally improves the stress transfer. This observation coincides with the significant improvement in the strength properties and modulus of the composite. Once again, the presence of voids and bubbles due to local foaming can be seen.

High content of filler (especially for the PU-WC 70 sample) resulted in the formation of agglomerates of particles and, as a result, the presence of irregular voids in the

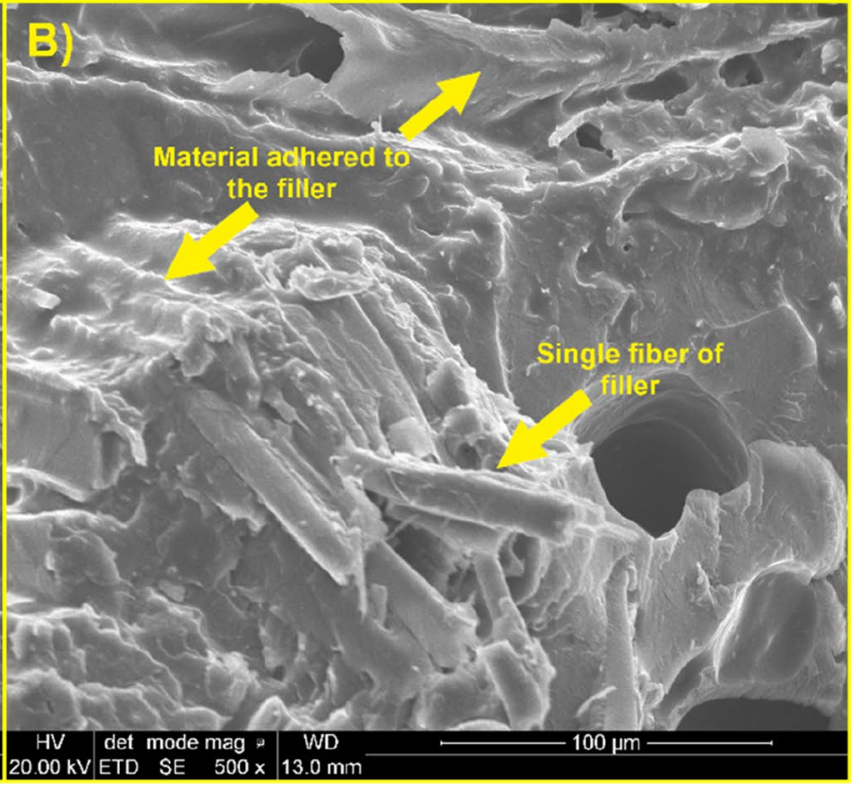

material. The presence of these irregular voids can cause local stress concentration, crack formation, and propagation leading to accelerated material fracture $(\mathrm{Ge}$ et al. 2004). This effect can confirm the decrease in flexural and impact strength of materials with high filler addition. Sample coded PU-WC 60 has the most homogeneous structure and it is difficult to distinguish both phases of composite. This is confirmed by the best mechanical parameters. Appropriate filler dispersion reduces the number of 

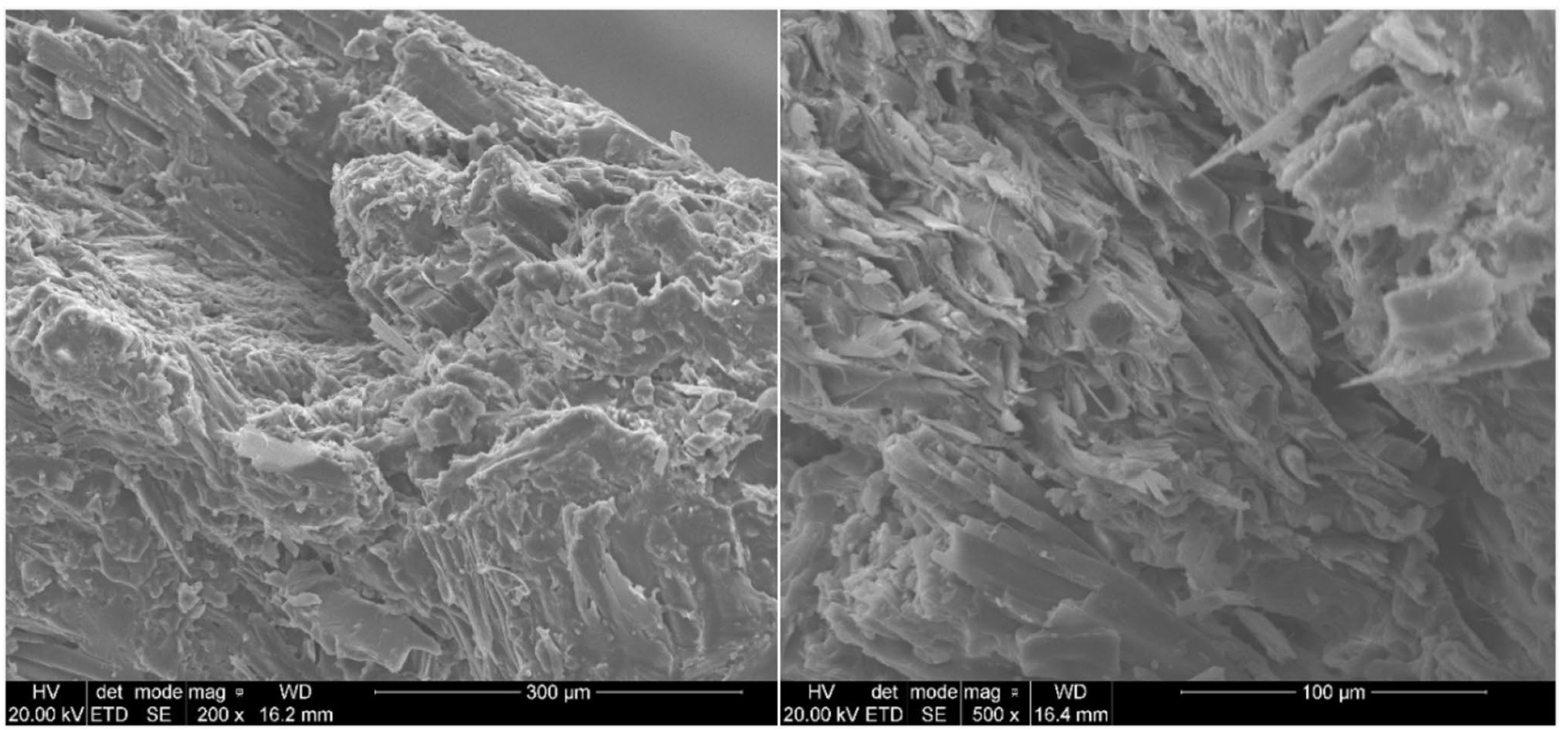

Fig. 12 SEM images of sample coded PU-WC 60
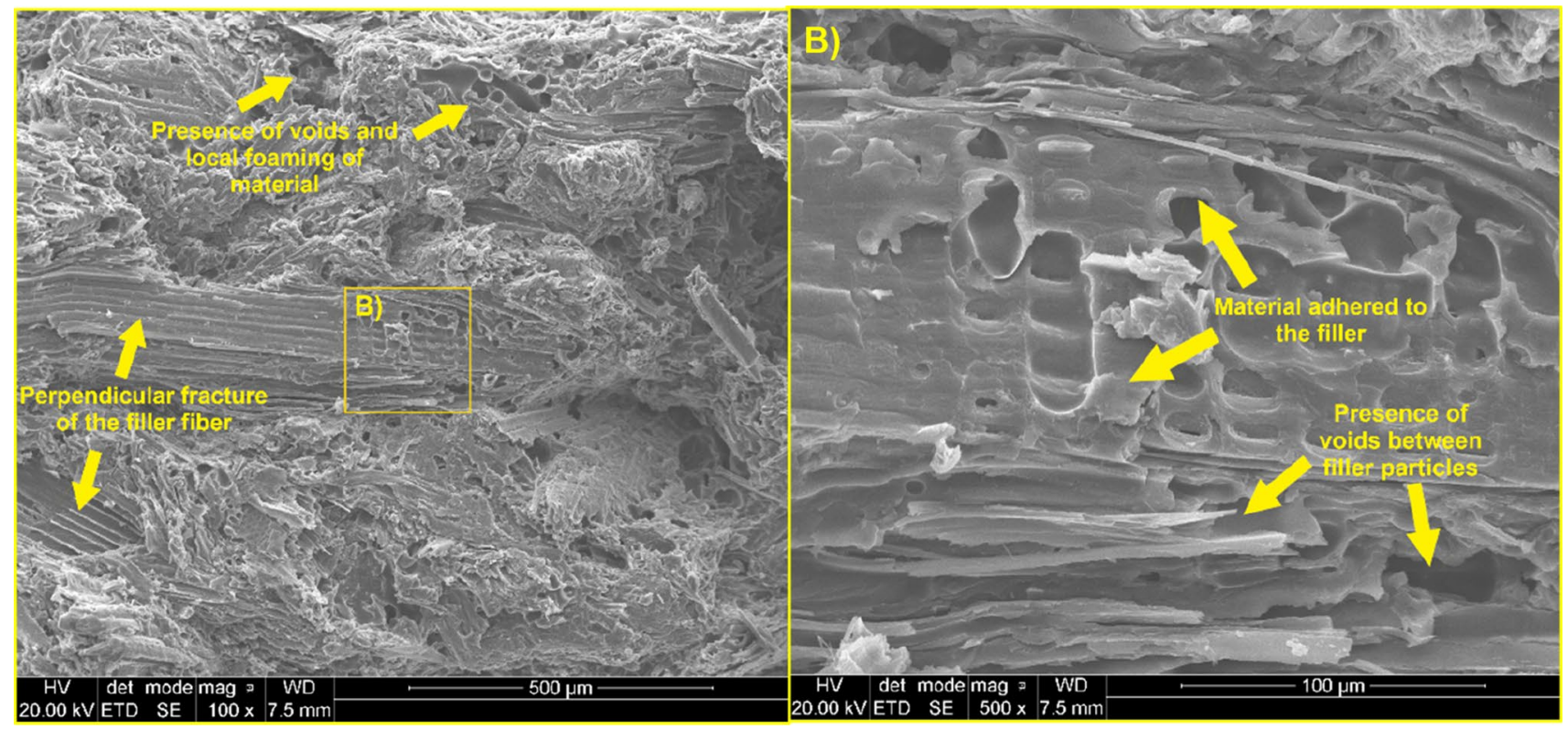

Fig. 13 SEM images of sample coded PU-WC 70

defects in the sample, increases interfacial adhesion, and optimizes the stress transfer between phases (Khan et al. 2019).

\section{Conclusion}

This research has presented a novel approach to the production of polyurethane wood composites (PU-WC) using previously synthesized biobased polyols obtained through biomass liquefaction. It has been confirmed that higher isocyanate indexes lead to stiffer materials with higher flexural strength, hardness, and impact strength, but also 
with significantly lower deformability. This effect may be due to the reaction of excess isocyanate with itself and formation of isocyanurate groups which result in a higher stiffness and degree of crosslinking. Moreover, the presence of isocyanurates in the PU structure led to an increase in the thermal stability of polyurethane materials. It was demonstrated that materials with a ratio of $\mathrm{NCO} / \mathrm{OH}=0.9$ (the highest deformability) and 1.1 (the highest flexural and impact strength) were found to be the most useful materials in the manufacturing of composites.

The addition of wood shavings caused a significant improvement in Young`s modulus, flexural strength, hardness, and impact strength with the addition of a filler up to $60 \%$. For PU-WC 60, the flexural strength has been improved from 26.42 (unfilled material) to $49.60 \mathrm{MPa}$ and the Young`s modulus increased from 0.94 to $2.86 \mathrm{GPa}$. The obtained results prove the reinforcing effect of the filler as well as the good compatibility of the filler with the matrix. The water absorption test showed that the samples reached the maximum saturation weight after $96 \mathrm{~h}$ and this parameter increases with the addition of wooden filler. The water absorption after $96 \mathrm{~h}$ increased from $8 \%$ for the PPG 1.1 to $22 \%$ for the PU-WC 70 sample.

The addition of filler leads to the deterioration of the thermal stability of the material. $\mathrm{T}_{5 \%}$ decreased from $244{ }^{\circ} \mathrm{C}$ for PPG1.1 to $225{ }^{\circ} \mathrm{C}$ for PU-WC 70. This may be due to high water absorption of wood inside the composites and slow water loss from the entire sample volume during the test. Scanning electron microscopy showed that the sample coded PU-WC $60 \%$ has the most homogeneous structure, which is connected to the best mechanical properties of this composite. Moreover, this test shows the presence of different kinds of material defects such as cracks, voids, and free spaces between the filler.

The findings of this study have several practical implications for the development of more sustainable components for the furniture, automotive, and construction industries, such as ecological boards, table tops, and laminates. The Presented method for polyurethane wood composite production provides a significant first step towards a greener alternative for materials produced mostly from non-renewable resources. Contrary to what has been reported in our previous works, these studies show the possibility of managing large amounts of wood waste in a simple technological process. Moreover, this research may be helpful in understanding the influence of the isocyanate index and addition of filler on the mechanical and thermal properties of these materials. Future studies should focus on improvement of the manufacturing method of PU-WC, interactions between the phases of the composite, and on the use of other wood-like wastes.
Acknowledgements The authors are grateful to Borsodchem for providing free isocyanate samples that helped us with our research.

Author contributions Conceptualization: $\mathrm{AO}$ and ŁP; Methodology: AO; validation: AO, ŁP and PK; Visualization: AO; Formal analysis: AO, PK, ŁP; Resources: AO, ŁP; Data curation: AO, ŁP; Writingoriginal draft preparation: AO; Writing — review and editing: AO, ŁP, PK; Supervision: ŁP, PK; Project administration: ŁP; All authors have read and agreed to the published version of the manuscript.

\section{Declarations}

Conflict of interest The authors declare no conflict of interest.

Open Access This article is licensed under a Creative Commons Attribution 4.0 International License, which permits use, sharing, adaptation, distribution and reproduction in any medium or format, as long as you give appropriate credit to the original author(s) and the source, provide a link to the Creative Commons licence, and indicate if changes were made. The images or other third party material in this article are included in the article's Creative Commons licence, unless indicated otherwise in a credit line to the material. If material is not included in the article's Creative Commons licence and your intended use is not permitted by statutory regulation or exceeds the permitted use, you will need to obtain permission directly from the copyright holder. To view a copy of this licence, visit http://creativecommons.org/licenses/by/4.0/.

\section{References}

Ayrilmis N, Taşdemir M, Akbulut T (2017) Water absorption and mechanical properties of PP/HIPS hybrid composites filled with wood flour. Polym Compos 38:863-869. https://doi.org/10.1002/ pc. 23647

Barbos JDV, Azevedo JB, da Silva M, Cardoso P et al (2020) Development and characterization of WPCs produced with high amount of wood residue. J Mater Res Technol 9:9684-9690. https://doi. org/10.1016/j.jmrt.2020.06.073

Borzecka M (2018) Absorbing the potential of wood waste in EU Regions and industrial bio-based ecosystems-BioReg. D.1.1. Report European Union's H2020, 1-48. http://bioreg.eu/assets/ delivrables/BIOREG\%20D1.1\%20EU\%20Wood\%20Waste\%20Sta tistics\%20Report.pdf

Deng W, Liu M, Zhang Q et al (2010) Acid-catalysed direct transformation of cellulose into methyl glucosides in methanol at moderate temperatures. Chem Commun 46:2668-2670. https://doi.org/ 10.1039/B925723C

European Union (2018) Directive 2018/851 amending Directive 2008/98/EC on waste Framework. Off J Eur Union (L-150/109-140)

Friedrich D (2018) Welfare effects from eco-labeled crude oil preserving wood-polymer composites: a comprehensive literature review and case study. J Clean Prod 188:625-637. https://doi. org/10.1016/j.jclepro.2018.03.318

Friedrich D (2021) Thermoplastic moulding of Wood-Polymer Composites (WPC): a review on physical and mechanical behaviour under hot-pressing technique. Compos Struct 262:113649. https:// doi.org/10.1016/j.compstruct.2021.113649

Gama N, Silva R, Carvalho APO et al (2017) Sound absorption properties of polyurethane foams derived from crude glycerol and liquefied coffee grounds polyol. Polym Test 62:13-22. https://doi.org/ 10.1016/j.polymertesting.2017.05.042 
Ge XC, Li XH, Meng YZ (2004) Tensile properties, morphology, and thermal behavior of PVC composites containing pine flour and bamboo flour. J Appl Polym Sci 93:1804-1811. https://doi.org/ 10.1002/app.20644

Ge XC, Zhu Q, Meng YZ (2006) Fabrication and characterization of biodegradable poly(propylene carbonate)/wood flour composites. J Appl Polym Sci 99:782-787. https://doi.org/10.1002/app.22557

Gosz K, Tercjak A, Olszewski A et al (2021) Bio-based polyurethane networks derived from liquefied sawdust. Materials (Basel) 14(11):3138. https://doi.org/10.3390/ma14113138

Guo K, Guan Q, Xu J, Tan W (2019) Mechanism of preparation of platform compounds from lignocellulosic biomass liquefaction catalyzed by bronsted acid: a review. J Bioresour Bioprod 4:202-213. https://doi.org/10.12162/jbb.v4i4.009

Hejna A, Kosmela P, Klein M et al (2018) Two-step conversion of crude glycerol generated by biodiesel production into biopolyols: synthesis, structural and physical chemical characterization. J Polym Environ 26:3334-3344. https://doi.org/10.1007/ s10924-018-1217-4

Hu S, Li Y (2014) Two-step sequential liquefaction of lignocellulosic biomass by crude glycerol for the production of polyols and polyurethane foams. Bioresour Technol 161:410-415. https://doi.org/ 10.1016/j.biortech.2014.03.072

Hu S, Wan C, Li Y (2012) Production and characterization of biopolyols and polyurethane foams from crude glycerol based liquefaction of soybean straw. Bioresour Technol 103:227-233. https://doi.org/ 10.1016/j.biortech.2011.09.125

Hu S, Luo X, Li Y (2014) Polyols and polyurethanes from the liquefaction of lignocellulosic biomass. ChemSusChem 7:66-72. https:// doi.org/10.1002/cssc.201300760

Ivdre A, Abolins A, Sevastyanova I et al (2020) Rigid polyurethane foams with various isocyanate indices based on polyols from rapeseed oil and waste PET. Polymers (Basel) 12(4):738. https://doi. org/10.3390/polym12040738

Jain NK, Gupta MK (2018) Hybrid teak/sal wood flour reinforced composites: mechanical, thermal and water absorption properties. Mater Res Express 5(12):125306. https://doi.org/10.1088/ 2053-1591/aae24d

Jiao L, Xiao H, Wang Q, Sun J (2013) Thermal degradation characteristics of rigid polyurethane foam and the volatile products analysis with TG-FTIR-MS. Polym Degrad Stab 98:2687-2696. https:// doi.org/10.1016/j.polymdegradstab.2013.09.032

Kasprzyk P, Błażek K, Datta J (2020) Microcrystalline cellulose management in the production of poly(ether-urethane)s- structure, morphology, and thermal characteristic. Fibers Polym 21:690700. https://doi.org/10.1007/s12221-020-9482-y

Khan MZR, Srivastava SK, Gupta MK (2019) Water absorption and its effect on mechanical properties of hybrid wood particulates composites. Mater Res Express 6:105305. https://doi.org/10.1088/ 2053-1591/ab34c3

Khan MZR, Srivastava SK, Gupta MK (2020) A state-of-the-art review on particulate wood polymer composites: processing, properties and applications. Polym Test 89:106721. https://doi.org/10.1016/j. polymertesting.2020.106721

Kim JK, Pal K (2010) Recent advances in the processing of wood-plastic composites. Springer-Verlag, Berlin

Kim SH, Kim BK, Lim H (2008) Effect of isocyanate index on the properties of rigid polyurethane foams blown by HFC $365 \mathrm{mfc}$. Macromol Res 16:467-472. https://doi.org/10.1007/BF03218546

Kosmela P, Hejna A, Formela K et al (2016) Biopolyols obtained via crude glycerol-based liquefaction of cellulose: their structural, rheological and thermal characterization. Cellulose 23:29292942. https://doi.org/10.1007/s10570-016-1034-7
Kosmela P, Kazimierski P, Formela K et al (2017) Liquefaction of macroalgae Enteromorpha biomass for the preparation of biopolyols by using crude glycerol. J Ind Eng Chem 56:399-406. https://doi. org/10.1016/j.jiec.2017.07.037

Kosmela P, Gosz K, Kazimierski P et al (2019) Chemical structures, rheological and physical properties of biopolyols prepared via solvothermal liquefaction of Enteromorpha and Zostera marina biomass. Cellulose 26:5893-5912. https://doi.org/10.1007/ s10570-019-02540-8

Kosmela P, Suchorzewski J, Formela K et al (2020) Microstructureproperty relationship of polyurethane foams modified with baltic sea biomass: microcomputed tomography vs scanning electron microscopy. Materials (Basel) 13(24):5734. https://doi.org/10. 3390/ma13245734

Laskowska AK (2017) Odpady drzewne w świetle polskich i unijnych przepisów prawnych (Wood waste under Polish and European Union law). Sylwan 159(5):355-360

Ndiaye D, Verney V, Askanian H et al (2013) Morphology, thermal behavior and dynamic rheological properties of wood polypropylene composites. Mater Sci Appl 04:730-738. https://doi.org/ 10.4236/msa.2013.411092

Olszewski A, Kosmela P, Mielewczyk-Gryń A, Piszczyk Ł (2020) Biobased polyurethane composites and hybrid composites containing a new type of bio-polyol and addition of natural and synthetic fibers. Materials 13:2028. https://doi.org/10.3390/ma13092028

Olszewski A, Nowak P, Kosmela P, Piszczyk Ł (2021) Characterization of highly filled glass fiber/carbon fiber polyurethane composites with the addition of bio-polyol obtained through biomass liquefaction. Materials 14(6):1391. https://doi.org/10.3390/ma14061391

Poletto M, Zattera AJ, Forte MMC, Santana RMC (2012) Thermal decomposition of wood: Influence of wood components and cellulose crystallite size. Bioresour Technol 109:148-153. https:// doi.org/10.1016/j.biortech.2011.11.122

Roig I (2018) Biocomposites for interior facades and partitions to improve air quality in new buildings and restorations. Reinf Plast 62:270-274. https://doi.org/10.1016/j.repl.2017.07.003

Szlachta M, Ordon K, Nowicka K, Pielichowska K (2021) Thermal properties of polyurethane-based composites modified with chitosan for biomedical applications. J Therm Anal Calorim 143:3471-3478. https://doi.org/10.1007/s10973-020-09283-w

Vale M, Mateus MM, Galhano dos Santos R et al (2019) Replacement of petroleum-derived diols by sustainable biopolyols in one component polyurethane foams. J Clean Prod 212:1036-1043. https:// doi.org/10.1016/j.jclepro.2018.12.088

Vimalanathan P, Venkateshwaran N, Santhanam V (2016) Mechanical, dynamic mechanical, and thermal analysis of Shorea robustadispersed polyester composite. Int J Polym Anal Charact 21:314 326. https://doi.org/10.1080/1023666X.2016.1155818

Wang H, Chen HZ (2007) A novel method of utilizing the biomass resource: rapid liquefaction of wheat straw and preparation of biodegradable polyurethane foam (PUF). J Chin Inst Chem Eng 38:95-102. https://doi.org/10.1016/j.jcice.2006.10.004

Yang H, Yan R, Chen H et al (2006) In-depth investigation of biomass pyrolysis based on three major components: hemicellulose, cellulose and lignin. Energy Fuels 20:388-393. https://doi.org/10. 1021/ef0580117

Yao Y, Yoshioka M, Shiraishi N (1995) Rigid polyurethane foams from combined liquefaction mixtures of wood and starch. J Japan Wood Res Soc 41:659-668

Yeoh FH, Lee CS, Kang YB et al (2020) Production of biodegradable palm oil-based polyurethane as potential biomaterial for biomedical applications. Polymers (Basel) 12(8):1842. https://doi.org/10. 3390/POLYM12081842 
Zhang J, Hori N, Takemura A (2019) Optimization of agricultural wastes liquefaction process and preparing bio-based polyurethane foams by the obtained polyols. Ind Crops Prod 138:111455. https://doi.org/10.1016/j.indcrop.2019.06.018
Publisher's Note Springer Nature remains neutral with regard to jurisdictional claims in published maps and institutional affiliations. 